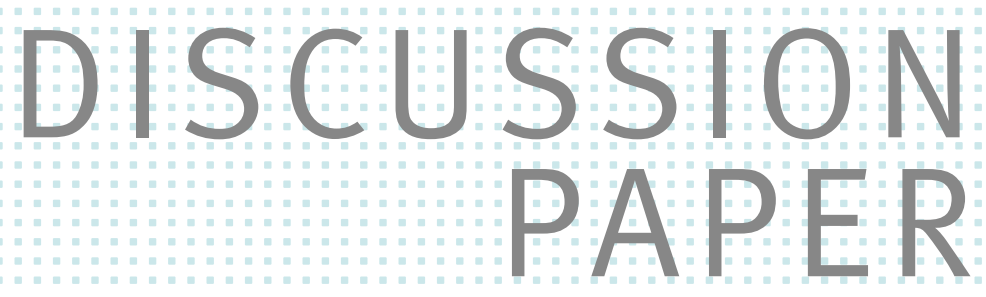

// EDUARD BRÜLL AND CHRISTINA GATHMANN

\title{
Evolution of the East German Wage Structure
}




\title{
Evolution of the East German Wage Structure
}

\author{
Eduard Brüll* \\ ZEW Mannheim \\ Christina Gathmann \\ University of Heidelberg, LISER, CESifo, IZA and ZEW
}

\begin{abstract}
We analyze the evolution of the wage structure in East Germany over the past two decades and compare it to West Germany. Both regions experienced a rise in wage inequality between 1995 and 2009 with wage dispersion in East Germany exceeding West Germany, esp. at the top. We also show that wage inequality is no longer rising in Germany and has even been declining in East Germany after 2009. Compositional changes of the workforce and selection along the employment margin play only a minor role as does the decline of union coverage for the rise in wage inequality. The adoption of minimum wages in selected industries, in contrast, explains all of the turnaround in East German wage inequality after 2009. Demand side changes seem to account for the rise in wage dispersion at the top.
\end{abstract}

Keywords: Wage inequality, Labor market institutions, Germany JEL codes: J21, J23, J24, J31, J42, J64

* Corresponding Author: Eduard Brüll, ZEW - Leibniz Centre for European Economic Research, L7, 1 D-68161 Mannheim, E-mail: eduard.bruell@zew.de.

We would like to thank Bernd Fitzenberger and Armin Seidlitz for making their imputation software available to us. We thank Bernd Fitzenberger, Christian Dustmann, Martin Biewen, Wolfgang Dauth, Albrecht Glitz, Joachim Möller, the participants at the Society of Labor Economists Meeting, the Annual Conference of the European Association of Labour Economists, and numerous institutions for helpful comments and suggestions. All remaining errors are our own. 


\section{Introduction}

Wage inequality has been rising in many countries drawing a lot of attention among scholars and the public alike. Most of the attention has focused on the United States (see the overviews in Katz and Murphy, 1992; Bound and Johnson, 1992; Card and DiNardo, 2002; Lemieux, 2006; Autor et al., 2008; Acemoglu and Autor, 2011). The dispersion of wages in the United States had increased both at the bottom and top of the wage distribution during the 1980s. Since the 1990s, wage gaps at the bottom part of the wage distribution have remained largely stable, while wage gaps at the top of the distribution have kept rising over time (Autor et al., 2016a). Contrary to the common perception that wage inequality remained unchanged in Continental Europe, Dustmann et al. (2009) document that wage dispersion has increased in West Germany between the 1980s and 2004 as well. While in the 1980s wage dispersion rose mostly at the top of the wage distribution, the 1990s also saw rising wage inequality at the bottom. Most of the movements at the top of the West German wage distribution seem to be technology driven demand shifts while movements at the bottom are better explained by supply shifts and the decline of union coverage in West Germany since the mid-1990s.

While the basic facts are undisputed, there is ongoing debate about the potential forces underlying the observed developments - and whether these are specific to the U.S. labor market, like the growth of high-skilled supply, or apply more broadly, like technological change, to all advanced economies. A key question is about the role of labor market institutions like unions and minimum wages in compressing the wage structure (see e.g. Lee (1999); Autor et al. (2016b) for minimum wages; and Card (1992); DiNardo et al. (1996) for unions) or, in accounting for the sizable cross-country differences in the evolution of wage inequality.

Interestingly, most recent studies on wage inequality in Germany still focus on West Germany arguing that the East German labor market is structurally too distinct to analyze the two together (Dustmann et al., 2009; Card et al., 2013). Other work study the German labor market as a whole and hence abstract from any structural differences between East and West Germany altogether (e.g. Dauth et al., 2014, 2017b; Dustmann et al., 2014). Dustmann et al. (2014), for instance, document how Germany evolved from being the "sick man of Europe" with high unemployment to Europe's economic superstar with strong employment growth even during the financial crisis. A third and entirely separate literature investigates the economic transition of the East German labor market (see e.g. Hunt, 2002; Orlowski and Riphahn, 2009) and its consequences for inequality (e.g. Biewen, 2001; Fuchs-Schündeln et al., 2010). Even more than twenty-five years after unification GDP per capita, wages and labor productivity in East Germany still lag behind, while unemployment rates exceed those in West Germany (Burda, 2008; Burda and Hunt, 2001; Burda and 
Severgnini, 2018). ${ }^{1}$ The lag persists despite sizable outmigration, in particular by young workers, from East Germany (Fuchs-Schündeln and Schündeln, 2009; Hunt, 2006; Uhlig, 2008) and despite large investments, which have made the East German economy more capital intensive on average than the West German economy (Keller, 2000; Burda and Hunt, 2001; Burda and Severgnini, 2018). The lack of convergence has lead many to label East Germany a second "Mezzogiorno" mirroring the sharp division in economic fortunes between Northern and Southern Italy (Keller, 2000; Sinn and Westermann, 2001; Uhlig, 2008).

It is unclear, however, whether East Germany experienced similar developments in its wage structure than West Germany. Has wage inequality also increased in East Germany and is it above or below West German levels? Furthermore, is the East German wage structure shaped by the same combination of supply and demand side forces than West Germany? Or, are there still peculiarities related to the transition process that shape the East German wage structure? Most importantly, while labor market institutions are uniform across the country, does their impact vary with the underlying structure of the labor market? In this paper, we provide answers to these important questions.

Using detailed administrative data on workers and their employers, we compare the evolution of wage inequality in East and West Germany over the past decades. We begin our analysis in 1995 to abstract from the turmoils of the immediate post-unification years when unemployment skyrocketed following the shut down of many former East German firms; and wages were pushed higher than productivity gains in East Germany to reduce the large wage gaps to West Germany (Akerlof et al., 1991). This study asks what has happened in the East German labor market in the twenty years after the initial turmoil.

The descriptive analysis reveals that the observed changes in the wage structure in East and West Germany over the past decades share some common features: wage inequality, irrespective of how we measure it, has risen substantially between 1995 and 2010. While there is almost no wage growth in the middle of the East or West German wage distribution, there are sizable wage gains at the top and real wage losses at the bottom. Since 2010, however, wage inequality leveled of and even reversed, mostly because of wage gains at the bottom of the wage distribution.

Despite these broadly similar patterns, there are two noteworthy differences between East and West Germany. The wage distribution in East Germany is actually more dispersed than in West Germany; this development is all the more surprising as wage levels are still 20 percent lower than in West Germany. The higher wage dispersion is primarily driven by sizable wage gains at the top of the East German wage distribution that exceed the wage gains at the top in West Germany. Wage earners at the 85th percentiles gained $20 \%$ but only $13 \%$ in West Germany between 1995 and

\footnotetext{
${ }^{1} \mathrm{~A}$ particular focus of macroeconomic studies has been on the question to what extent the East German economy has converged to its perceived West German benchmark.
} 
2014. The second difference is that the decline in wage inequality after 2009 is more pronounced in East Germany than in West Germany. Most of this decline comes from rising wages at the bottom. Between 2010 and 2014, wages at the 15th percentiles recover almost half of the wage losses that occurred between 1995 and 2009.

We then investigate what factors explain the evolution of the wage structures in the East; and to what extent these forces differ from those in West Germany. We have five main findings. First, we show that compositional changes through educational upgrading and demographic aging have little influence on the structure of wages. If anything, top wage inequality would have increased slightly less in East and West Germany when the composition of the workforce is held constant. Second, East Germany lost about 10\% of its population between 1995 and 2010 though population levels have stabilized since. East German employment also plummeted by $10 \%$ between 1995 and 2004, while employment has increased again after 2004 - though not as much as in West Germany. We first show that the average labor market leaver is somewhat below the median earner, but above the 15th percentile in terms of wages and observable characteristics. Similarly, the average entrant after 2004 is also located somewhere between the 15th and 50th percentile of the wage distribution. Imputing wage for leavers until 2004 and entrants since 2004 suggest few effect for top end wage inequality (the 85-50 wage gap) but slightly reduces wage inequality at the bottom (the 50-15 wage gap).

Our third finding is that the decline of union coverage plays no role for the rising wage dispersion in East Germany - though it is the primary driver of rising wage dispersion at the bottom in West Germany. This result is even more surprising as union coverage declined even more dramatically in East Germany than in West Germany between 1995 and 2004. The main reason is that union coverage rates are much lower in the service sector, which makes up much of the jobs at the bottom of the East German wage distribution. In West Germany, many low-wage workers work in the manufacturing sector where union coverage have traditionally been high. Hence, the plummeting coverage rates do little harm to East German wages at the bottom in East Germany, but are responsible for some of the wage losses at the bottom in West Germany. As coverage rates increase at higher wage percentiles, wages at the top of the East German wage distribution would have been even higher in the absence of declining coverage rates. We find no such effect for top end wages in West Germany.

The fourth finding is that the adoption of minimum wages in selected industries is the main explanation for the turnaround in East German wage inequality after 2009. East German wages are about $25 \%$ lower than West German wages, while minimum wages are either uniform across the country or only slightly lower in East Germany - making the effective minimum wage considerably higher in East Germany than in West Germany. We then show that the sector-specific minimum wages can explain all of the turnaround in wage inequality at the bottom of the East German 
distribution since 2010. While minimum wages also raise West German wages at the bottom, the effect on wage dispersion is much more modest.

We then turn to the demand side for explaining the stark increase in top end wage inequality prior to 2010. In East Germany, one-third of the rise in the 85-50th wage gap is accounted for by wage differentials between education and age groups. Moreover, we show that an additional $30 \%$ of the rising 85-50 wage gap in East Germany is accounted for by inter-industry differentials. We find little evidence that these are driven by economic restructuring of the East German economy shifting employment shares from manufacturing and construction to the service industry. Even more surprisingly, we also find little evidence that the inter-industry differentials are driven by trade exposure or polarization. While routine-biased technological change generates employment polarization, it has little effect on the East or West German wage structure. Similarly, the sizable expansion of trade, a key motor for Germany's strong economic performance and employment growth, has only small wage effects. Hence, wage dispersion in East Germany, where the economy's export share has traditionally been low, is unaffected by trade exposure. The contribution of trade to top end wage inequality is somewhat more important in West Germany with its many exportoriented industries, but remains modest overall.

The paper proceeds as follows. The next section introduces the data sources we use to analyze the evolution of the wage structure. Section 3 provides several stylized facts about wage growth and wage inequality in East Germany over the past decades and compares it to West Germany. Section 4 analyzes whether shifts on the labor supply side may account for the observed changes in the East German wage structure. Section 5 assesses the influence of labor market institutions on the evolution of the German wage structure, while section 6 turns to the labor demand side. Finally, section 7 concludes.

\section{Data Sources}

Our analysis mainly relies on individual social security records and matched employer-employee data supplemented by aggregate industry-level administrative data; the latter are discussed in more detail in appendix A.

\subsection{Individual Social Security Records, 1995-2014}

Our main data are a $2 \%$ random sample of the population of workers and plants covered by the social security system in Germany. ${ }^{2}$ We observe for each individual whether she is employed within the social security system or whether she collects unemployment benefits as of June 30th each year. The panel structure allows us to follow each employee even if a worker changes jobs or moves to

\footnotetext{
${ }^{2}$ The social security data cover around $80 \%$ of the German labor force excluding civil servants, military personnel and the self-employed.
} 
another plant or region. As we are interested in the wage structure of the East German economy, we focus on individuals whose workplace is based in one of the new states (including Berlin) or who draw unemployment benefits in East Germany. We thus include employees originating from West Germany or abroad in the East German sample if they are employed or registered as unemployed in East Germany. Below, we investigate internal migration and commuting from East to West Germany, for instance, as one channel of labor supply adjustment.

The wage variable records the average daily wage for the employment spell that contains the reference date (June 30th). ${ }^{3}$ Like most social security data, our wage variable is right-censored at the social security limit. As wages are lower in East Germany, the share of censored wages in our data is lower in East Germany (6.6\%) than in West Germany (13.6\%). We impute censored wages under the assumption that the error term in the wage regression is normally distributed allowing for separate variances by year and gender separately for East and West Germany. We convert wages to 2014 prices using the national consumer price index.

We observe the detailed occupational and industry classification (at the 3-digit level) of each employment spell. We distinguish three skill groups based on the highest educational qualification. A person is low-skilled if she has neither finished a high school or vocational degree. An individual is medium-skilled if she has completed an apprenticeship or graduated from high school (Abitur). A person is high-skilled if she graduated from college or university. In the raw data, the education variable is missing for about $20 \%$ of the observations and contains some inconsistencies over time. We use the panel structure of the data to impute missing educational information and remove inconsistencies using past and future spells following (Fitzenberger et al., 2006). We keep the small number of observations with missing education even after imputation.

We restrict our sample to individuals between the ages of 20 and 62. We exclude irregular, marginal and seasonal employment, apprenticeship and partial retirement spells. Further, we focus in our analysis on full-time workers, which we define as working at least 30 hours per week. ${ }^{4}$ Finally, we restrict our analysis to men for two reasons. First, a change of reporting full-time work in the social security records in 2011 renders it impossible to define a sample of women working full-time consistently over time. ${ }^{5}$ Second, our main focus lies on understanding the determinants of the wage structure in East and West Germany over three decades. The differences between men and women would add yet another layer of complexity, which we leave for future research.

\footnotetext{
${ }^{3}$ Because employers are required to update records only at the end of each year, this variable may capture wage changes that occurred from January to December of the same year.

${ }^{4}$ While information on actual working hours is not available over the full time period we study, the data contain a indicator for full-time and part-time work. A job is classified as full-time if working hours per week correspond or exceed the standard working time for full-time workers defined in the collective bargaining agreement of the firm or respective industry.

${ }^{5}$ Prior to 2011, transitions between full- and part-time work within the same establishment were often not reported by employers. The change in reporting requirements in 2011 thus generated a huge spike in the share working parttime in 2011 among women, but not among men (see Ludsteck and Thomsen, 2016, for a detailed discussion).
} 
Aggregate economic indicators, shown in appendix table B1, reveal that the transition from a socialist to a functioning market economy has been to a long and ropy process. At our starting point in 1995, five years after unification, GDP per capita was almost one-third lower in East Germany than in West Germany. By 2014, East Germany's GDP per capita is $25 \%$ below that of West Germany. The lower level of economic activity is also evident in wages. In 1995, median wages in East Germany are 30 percent lower than in West Germany with very slow convergence until 2014. Yet, employment rates have increased and unemployment rates decreased a lot though unemployment rates remain above West German levels in 2014. Actually, East German wages in 2014 are still below the wage levels West Germany had in 1995. We also observe some convergence in the industry structure between East and West Germany. East Germany still has a smaller manufacturing sector than West Germany, but the employment gap between East and West Germany has narrowed substantially - from $18 \%$ in 1995 to $8 \%$ in 2014 . The service sector has been larger in East Germany, but the employment gap narrowed to around $5 \%$ in 2014 . The East German construction sector, which employed almost $18 \%$ of all employees in 1995, has shrank to a more reasonable $9 \%$ by 2014 .

\subsection{Linked Employer-Employee Data, 1996-2014}

Our main data do not contain information on union coverage, which has been shown to influence the wage structure in West Germany during the 1990s and 2000s (Dustmann et al., 2009; Card et al., 2013). To analyze how changes in union density have affected the wage structure in East Germany, we rely on a linked employer-employee data set. The matched data combine the IAB Establishment Panel, a large-scale survey of plants, with social security records of all workers who were employed in the surveyed firms as of June 30 each year (see Klosterhuber et al., 2016, for a detailed description).

The IAB Establishment Panel has surveyed plants in West Germany since 1993, but covers East German plants only since 1996. As the IAB establishment panel oversamples large establishments and small states, we employ cross-sectional weights for adjustment. An establishment can recognize a trade union either by joining an employers' association or through direct negotiations between the firm and the union. Therefore, the union variable in the matched data distinguishes between industry-level agreements, which are negotiated at a regional and industry level, firm-level agreements through direct negotiations between the plant and a union, or no agreement at all. 


\section{Stylized Facts about the Wage Structure in East and West Ger- many}

We begin with several stylized facts about the East German wage structure and compare them to the better known West German patterns. Figure 1 plots commonly used measures of wage inequality: the standard deviation of log wages, the log wage gap between the 85th and 50th percentiles (the 80-50 Wage Gap) and the log wage gap between the 50th and 15th percentiles (the 50-15 Wage Gap). ${ }^{6}$ The left panel of figure 1 refers to East Germany, the right panel to West Germany.

Overall wage inequality rises steadily in both East and West Germany between 1995 and 2009. The fanning out of the wage distribution comes to a stop and even reverses after 2009. While the standard deviation of wages rose in East Germany from 0.37 to 0.51 in a 15-year period (19952009), it declined to 0.46 over the next five years (2010-2014). Comparing the evolution in the upper and lower part of the wage distribution over time suggests that the reversal is explained by a reduction in inequality at the bottom (the 50-15 wage gap) and a leveling off at the top (the 85-50 wage gap) after 2009 .

Figure 1: Evolution of Wage Inequality
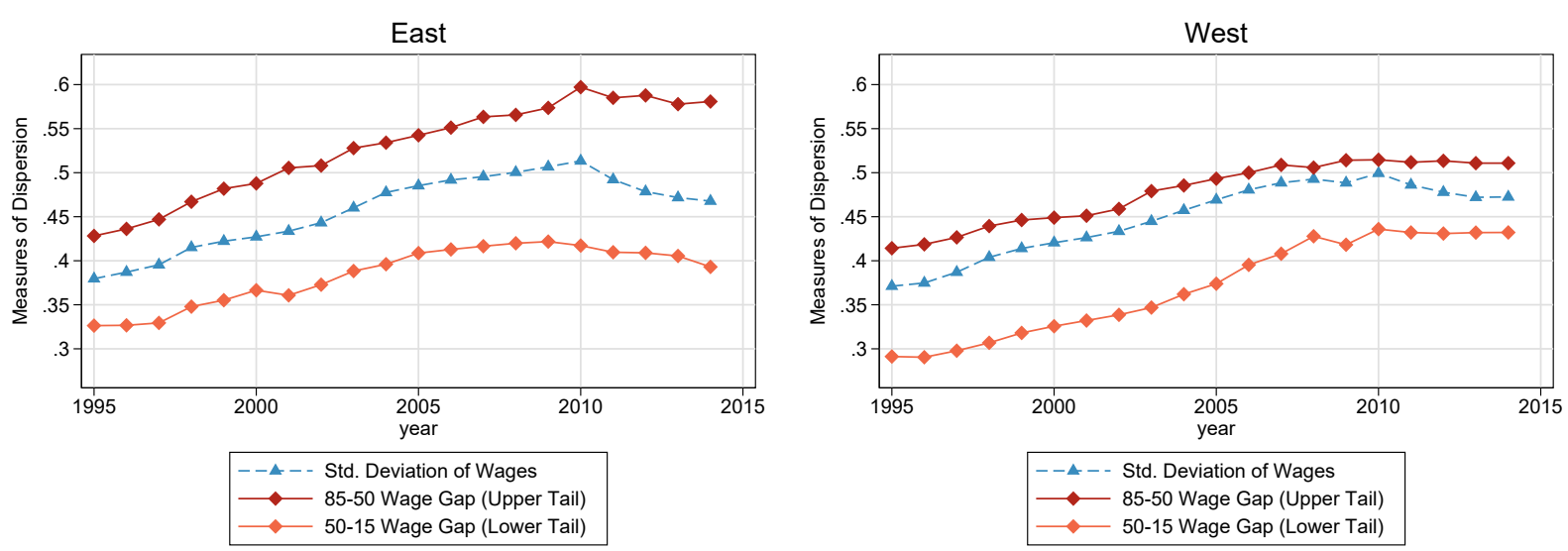

Note.- The figures plot three measures of wage inequality: The standard deviation of log wages, the log wage gap between the 85 th and 50 th percentiles and the log wage gap between the 50th and 15 th percentiles. Source: $2 \%$ SIAB Sample for male full-time workers between the ages of 20 and 62 .

The most striking feature of figure 1 is that wage inequality at the top has been rising faster in East Germany (left panel) than in West Germany (right panel). While the 80-50 log wage gap was around 0.42 in East and West Germany in 1995, it rises to 0.6 in East Germany until 2009, but to only 0.5 in West Germany. The higher dispersion at the top is all the more noteworthy as East German wages are on average about 25 percent lower than wages in West Germany (see table

\footnotetext{
${ }^{6}$ All measures of wage inequality are based on imputed wages rather than censored wages. The percentile wage gaps are not affected by the imputation as less than $0.1 \%$ of the observations below the 85th percentile are censored. The standard deviation of wages is by definition somewhat lower for censored wages, but its evolution over time is very similar to that for imputed wages in both regions.
} 
B1). ${ }^{7}$ In contrast, the 50-15 wage gap shows a similar development in East and West, though the rise is slightly more pronounced in West Germany and shows no reversal after 2009.

To track real wage gains and losses across the wage distribution, figure 2 plots the evolution of real daily wages at the 15 th, 50 th and 85 th percentile indexed to 1995 . Consistent with the rise in overall inequality, the wage distribution has been fanning out in both West and East Germany over the past two decades. There is little real wage growth (of only $2 \%$ ) for the median wage earner in East and West over the 20-year period. Yet, the top of the distribution has experienced sizable wage gains in both parts of the country, while the bottom of the distribution suffered real wage losses. A closer look reveals striking differences in the observed wage gains and losses between

Figure 2: Real Wage Growth in East and West Germany
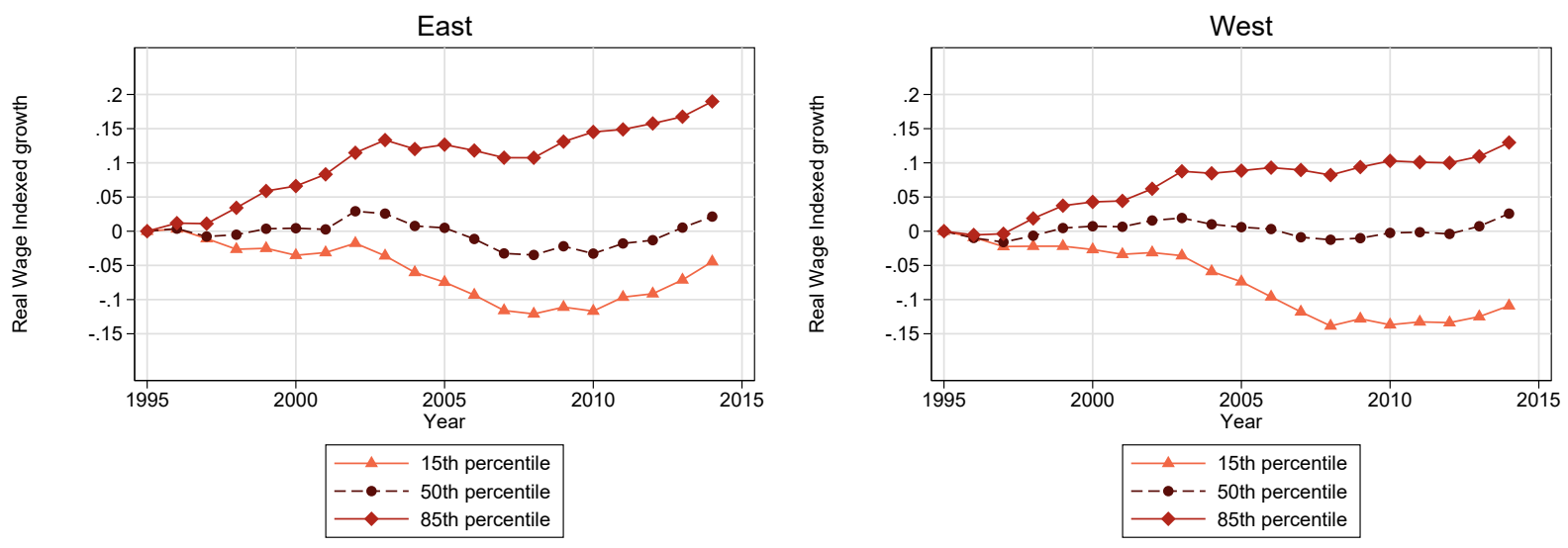

NotE.- The figures show real wage growth at the $15 \mathrm{th}, 50 \mathrm{th}$, and 85 th percentiles of the wage distribution relative to 1995.

Source: $2 \%$ Social Security Records (SIAB) for male full-time workers between the ages of 20 and 62 .

East and West. Wage gains at the top of the distribution are much larger in East Germany than in West Germany: Real wages at the 85th percentile rose by 19\% in East Germany between 1995 and 2014; in West Germany, real wages at the top grew by only $13 \%$ - or a third less than in East Germany. At the bottom of the wage distribution, wages evolved similarly in East and West until about 2009: Real wages at the 15 th percentile declined by $12-14 \%$ in both parts of the country between 1995 and 2009. After 2009 however, wages at the bottom recovered more in East Germany than in West Germany. Wages at the 15 th percentile grew by $7 \%$ in the East, but only by $3 \%$ in the West between 2010 and 2014. As a result, over the whole period, real wages at the 15th percentile declined by $-11 \%$ in West Germany, but only by $-4 \%$ in East Germany. The pattern of relative wage gains and losses shown in figure 2 also explain why the 50-15 wage gap has been rising until 2009 (see figure 1): the rise has less to do with wage gains by the median earner, but more so with wage losses at the bottom of the German wage distribution.

\footnotetext{
${ }^{7}$ The fact that wage inequality in East Germany exceeds that of West Germany at the top of the distribution is not an artefact of censoring. The wage gaps shown in figure 1 are based on imputed and hence, uncensored wages. Furthermore, we find a very similar pattern if we plot the 75-50 log wage gap, for which the share of censored wages is very small.
} 
Our results speak against the widespread view that nothing has changed in East Germany since the immediate post-unification period. On the contrary, wage inequality in East Germany has increased even more than in West Germany between 1995 and 2014, especially at the top of the distribution. While the wage distribution fanned out continuously in both parts of the country prior to 2010, the development has reversed in East Germany after 2009 - mostly because of relative gains at the bottom of the East German wage distribution. The reversal of wage inequality stand in stark contrast to developments in the United States where wage inequality, esp. at the top of the wage distribution, continues to increase.

\section{Supply-Side Changes}

The observed shifts in the wage structure may be influenced by changes in workforce composition or by the large swings in employment through un- or non-employment and migration. We analyze each of these factors in turn.

\subsection{Workforce Composition}

Table 1 traces the composition of the workforce and the wage structure in East Germany across education and age groups. We report the employment share, the 85-50 and 50-15 log-wage gaps by education and age in 1995, 2004 and 2014. All reported values are calculated using imputed and hence, uncensored wages. To the extent that our imputation method does not fully capture the long right tail in wages, the 85-50 wage gap might understate true wage inequality at the top among the group of high-skilled. The corresponding table for West Germany is contained in table B2 in the appendix. The employment shares suggest sizable educational upgrading of the East German workforce over time. The share of low-skilled workers (without a high school or vocational degree) declines from $4.2 \%$ to $1.8 \%$, while the share of workers with a college or university degree increases from $15.4 \%$ to $19.7 \%$ of the same period. A comparison with West Germany, reveals that East Germany actually has a more educated workforce than West Germany - a legacy of its socialist past: the share of low-skilled, i.e. individuals with no high school or vocational degree, is three times higher in West Germany (5.8\% in 2014) than in East Germany (only 1.8\% in 2014). Yet, the share of college-educated increased much more in West Germany - in fact, almost doubled from $10.5 \%$ in 1995 to $20 \%$ in 2014 - than in East Germany.

The employment shares further indicate that the East German workforce is aging. The share of young employees (20- to 36-year-olds) in all education groups declines from $42.5 \%$ in 1995 to $31.6 \%$ in 2014. The share of older workers (47- to 62-year-olds) in turn expands from $26.6 \%$ to $41.5 \%$ over the same period. A similar pattern is observed in West Germany (see table B2). Demographic aging and skill upgrading may account for the rising East German wage inequality 
if the dispersion in unobserved skills, for instance, and hence, the variability in wages is higher among older and more educated workers (Lemieux, 2006). Yet, overall wage dispersion does not

Table 1: East German Wage Inequality by Education and Age

\begin{tabular}{|c|c|c|c|c|c|c|c|c|c|}
\hline & \multicolumn{9}{|c|}{ Low Education } \\
\hline & \multicolumn{2}{|c|}{1995} & \multicolumn{2}{|c|}{2004} & \multicolumn{2}{|c|}{2014} & 1995 & 2004 & 2014 \\
\hline & 50-15 gap & 85-50 gap & 50-15 gap & 85-50 gap & 50-15 gap & 85-50 gap & \multicolumn{3}{|c|}{ Employment Share } \\
\hline $20-36$ & 0.43 & 0.33 & 0.61 & 0.46 & 0.29 & 0.44 & $1.7 \%$ & $1.2 \%$ & $1.0 \%$ \\
\hline $36-47$ & 0.34 & 0.34 & 0.73 & 0.38 & 0.42 & 0.46 & $1.2 \%$ & $1.0 \%$ & $0.3 \%$ \\
\hline $47-62$ & 0.34 & 0.34 & 0.50 & 0.39 & 0.57 & 0.35 & $1.3 \%$ & $0.8 \%$ & $0.5 \%$ \\
\hline \multirow[t]{4}{*}{ All } & 0.39 & 0.33 & 0.67 & 0.48 & 0.41 & 0.50 & $4.2 \%$ & $3.0 \%$ & $1.8 \%$ \\
\hline & \multicolumn{9}{|c|}{ Medium Education } \\
\hline & \multicolumn{2}{|c|}{1995} & \multicolumn{2}{|c|}{2004} & \multicolumn{2}{|c|}{2014} & 1995 & 2004 & 2014 \\
\hline & 50-15 gap & 85-50 gap & 50-15 gap & 85-50 gap & 50-15 gap & 85-50 gap & \multicolumn{3}{|c|}{ Employment Share } \\
\hline $20-36$ & 0.28 & 0.30 & 0.33 & 0.39 & 0.31 & 0.39 & $36.9 \%$ & $26.7 \%$ & $25.2 \%$ \\
\hline $36-47$ & 0.29 & 0.34 & 0.34 & 0.42 & 0.34 & 0.48 & $24.4 \%$ & $30.0 \%$ & $21.0 \%$ \\
\hline $47-62$ & 0.32 & 0.40 & 0.37 & 0.42 & 0.34 & 0.46 & $19.2 \%$ & $23.0 \%$ & $32.3 \%$ \\
\hline \multirow[t]{4}{*}{ All } & 0.30 & 0.33 & 0.34 & 0.42 & 0.33 & 0.44 & $80.4 \%$ & $79.7 \%$ & $78.5 \%$ \\
\hline & \multicolumn{9}{|c|}{ High Education } \\
\hline & \multicolumn{2}{|c|}{1995} & \multicolumn{2}{|c|}{2004} & \multicolumn{2}{|c|}{2014} & 1995 & 2004 & 2014 \\
\hline & 50-15 gap & 85-50 gap* & 50-15 gap & 85-50 gap* & 50-15 gap & 85-50 gap* & Emp & pyment & Share \\
\hline $20-36$ & 0.38 & 0.32 & 0.45 & 0.36 & 0.41 & 0.28 & $3.9 \%$ & $3.6 \%$ & $5.4 \%$ \\
\hline $36-47$ & 0.35 & 0.32 & 0.43 & 0.34 & 0.48 & 0.29 & $5.5 \%$ & $6.2 \%$ & $5.6 \%$ \\
\hline $47-62$ & 0.35 & 0.32 & 0.55 & 0.36 & 0.57 & 0.35 & $6.1 \%$ & $7.4 \%$ & $8.7 \%$ \\
\hline All & 0.37 & 0.32 & 0.49 & 0.34 & 0.49 & 0.34 & $15.4 \%$ & $17.3 \%$ & $19.7 \%$ \\
\hline
\end{tabular}

Note.- The table shows 85-50 and 50-15 log wage gaps in East Germany both across and within age and education groups as well their employment shares in 1995, 2004 and 2014. The results are based on imputed and hence, uncensored wages. The star denotes that the the 85 th wage percentile for the high-skilled is above the censoring bound.

Source: $2 \%$ SIAB Sample for East German male full-time workers between 20 and 62 years of age

increase monotonically with education: instead, wage dispersion is highest for low-skilled workers throughout the period and lowest for the medium-skilled. There is a monotonic increase in wage dispersion across age groups for each education group, however (except the 85-50 wage gap for the low-skilled) over time. Furthermore, wage dispersion within education and age groups rises substantially between 1995 and 2004, but levels off or even declines for most age and education groups between 2004 and 2014. Exceptions are the 47- to 62-year-olds where inequality increases for all education groups over time; and the 85-50 wage gap of the low- and medium-skilled 36- to 47-year-olds.

Hence, while compositional changes are likely to play some role, the evolution of within-group inequality suggest that workforce composition cannot explain much of the observed changes in the East German wage structure. The wage patterns for East Germany in table 1 differ from those observed in West Germany (see table B2 in the appendix) where overall and within-group inequality have been rising throughout the 1995-2014 period. They also appear to differ from other advanced economies like the United States, which has experienced a long-term rise in both overall and within-group inequality (Autor et al., 2008).

We next assess the quantitative importance of compositional changes for the wage structure 
using the inverse probability weighting approach by DiNardo et al. (1996). The basic idea is to decompose the wage distribution in period $\mathrm{t} f_{c}(w \mid t)$ into a price effect and a composition effect as follows:

$$
f_{c}(w \mid t)=\int f(w \mid x, T=t) \psi_{x} d F(x, T=t) \quad \text { with } \quad \psi_{x}=\frac{d F(x \mid T=1995)}{d F(x \mid T=t)}
$$

The weight $\psi_{x}$ reflects the over- or underrepresentation of the characteristics $x$ in the current period $t$ relative to the reference period (here, 1995). Technically, $\psi_{x}$ is an inverse probability weight computed from the propensity score of being observed in the reference period conditional on observed characteristics. We estimate the propensity score using predetermined variables only: eight age groups and three education groups as well as a full set of interactions.

Holding the workforce composition constant at 1995 levels but allowing prices of different skill groups to change, we then construct conterfactual wage distributions for each year $t$ between 1996 and 2014. Reweighting the 2014 wage distribution to the 1995 demographics, for instance, generates the counterfactual wage distribution if the demographic characteristics had remained at their 1995 level, but employees would be paid according to 2014 skill prices. Note that the decomposition method abstracts from general equilibrium effects by assuming that skill prices do not respond to compositional changes. Hence, the reweighting approach does not account for changes in skill prices resulting from relative supply changes; we examine the contribution of changing skill prices in more detail in Section 4.3 below. Figure 3 plots the actual and counterfactual 85-50 and 50-15 wage gaps for East Germany (left panel) and West Germany (right panel). Wage dispersion would have evolved very similarly in both parts of the country over time if we held the education and age composition fixed at their 1995 levels (the dashed lines). Compositional changes matter more at the upper tail (85-50 wage gap) of the wage distribution - both in East and in West Germany. At the bottom of the wage distribution, in contrast, compositional adjustments play little role in East Germany and almost no role in West Germany. These conclusions do not depend on the choice of reference period: we find similar counterfactual wage gaps if we re-weigh to the workforce composition in 2004 or 2014 instead (see table B4 in the appendix). ${ }^{8}$

\footnotetext{
${ }^{8}$ Looking at individual quantiles, wage growth from 1995 to 2004 would have been slightly weaker across the entire distribution when the demographic composition is held constant. Wage losses at the bottom of the distribution would have been more pronounced ( $7.5 \%$ rather than $6 \%$ ) and wage gains at the 85 th percentile would have been $10 \%$ rather than the actual $12 \%$. For the 2004-2014 period, workforce composition has little effect on observed wage patterns in East Germany.
} 
Figure 3: Wage Gaps Adjusted to 1995 Demographics
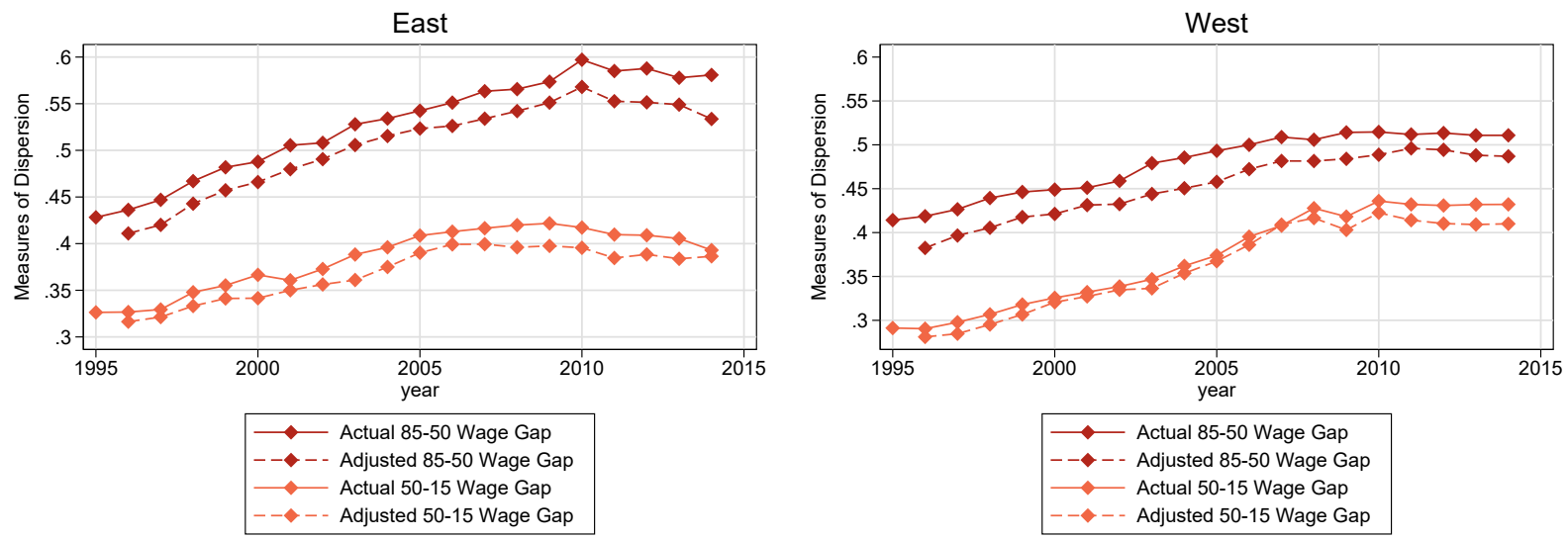

Note.- The figures plot the (log) wage gap between the 85th and 50th percentiles and the (log) wage gap between the 50th and 15 th percentiles. The solid lines show actual wage gaps and the dashed lines counterfactual wage gaps after adjusting workforce composition to 1995 demographics. The left panel refers to East Germany, the right one to West Germany.

Source: $2 \%$ SIAB Sample for male full-time workers between the ages of 20 and 62 .

Figure 3 does not distinguish between- and within-group (or residual) inequality. Residual wage inequality could rise if there is an unobserved skill like ability whose price is also rising over time. Alternatively, residual wage inequality could be rising because the variance of wages increases with age and education (Juhn et al., 1993; Lemieux, 2006). To investigate this, we perform the same re-weighting approach on residual wages, which we obtain from a Mincer-type regression of log wages on three education groups, eight age groups and a full set of interactions, estimated separately for each year. Figure 4 reveals that compositional changes are somewhat more important for explaining residual inequality at the bottom of the wage distribution. Its explanatory power for residual wage inequality is with at most $10 \%$ still modest, however. In fact, residual wage inequality at the top and bottom still follows the same time pattern in both East and West whether we account for workforce composition or not. As such, compositional changes between 1995 and 2014 cannot account for the rise in overall or residual wage inequality, a result that also holds for alternative choices of the reference period (see appendix table B4). Finally, a comparison of figures 3 and 4 shows that residual inequality in East Germany increases more slowly than overall inequality between 1995 and 2010: while the overall 85-50 wage gap rises by $0.17 \log$ points, the residual 85-50 wage gap rises by only 0.12 . Hence, between-group inequality plays an important role in East Germany at the top of the distribution. In West Germany, all of the rise in the 85-50 wage gap by $0.10 \log$ points occurs within education and age groups. At the bottom of the wage distribution, we observe the opposite pattern: all of the increase in East Germany's 50-15 wage gap is accounted for by within-group wage differences. In West Germany in contrast, the overall 50-15 wage gap increases by $0.14 \log$ points, while the residual 50-15 wage gap rises by 0.11 log points - hence, changes in wage differentials between skill groups account for 

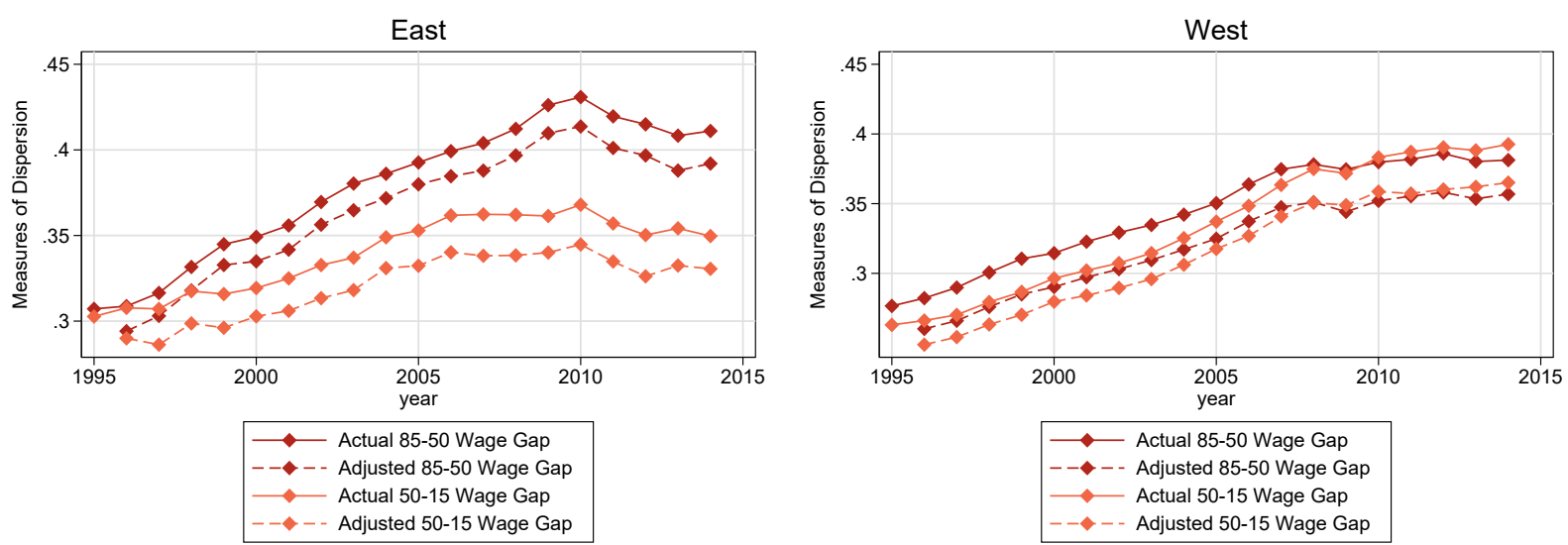

Note.- The figures plot the residual wage gap (in logs) between the 85th and 50th percentiles and the log wage gap between the 50th and 15th percentiles. The solid lines show actual residual wage gaps, the dashed lines residual wage gap after adjusting workforce composition to 1995 demographics. The left panel refers to East Germany, the right one West Germany.

Source: $2 \%$ SIAB Sample for male full-time workers between the ages of 20 and 62 .

Overall then, compositional changes in the workforce can neither explain the striking growth in East German wage inequality, esp. at the top, until 2010 nor its turnaround since then. We therefore turn next to the question whether selective changes along the employment margin had an influence on the East German wage structure.

\subsection{Changes along the Employment Margin}

East Germany, like many post-communist countries in Central and Eastern Europe, experienced sizable declines in population and employment during the transition period. Figure 5, which plots total population and total employment of East and West Germany relative to 1995 reflects this pattern. During the 1995-2014 period, the total population in East Germany shrank by $10 \%$. Between 1995 and 2009, East Germany lost about 100,000 inhabitants each year; since 2010, the trend has been reversed and population numbers have stabilized. More than half of the decline in East Germany's population is accounted for by the substantial net outmigration to West Germany as shown in the left panel of figure B1 in the appendix. ${ }^{9}$ Outmigration to West Germany came to a halt by 2014 , however. The modest population gains since 2010 are accounted for by inflows of international migrants to East Germany (mostly Berlin) as shown in the right panel of figure B1 in the appendix. The population in West Germany, in contrast, has actually increased slightly between 1995 and 2014 as West Germany absorbed the positive net immigration from abroad (except during the 2008/2009 financial crisis when net migration rates were negative) and the net

\footnotetext{
${ }^{9}$ In addition, fertility rates plummeted after unification (see e.g. Chevalier and Marie, 2017) but recovered to West German levels by 2008. Since 2008, fertility rates in East Germany exceed West German fertility rates (Arntz et al., 2014).
} 
outmigration from East to West Germany.

Figure 5: Employment and Population

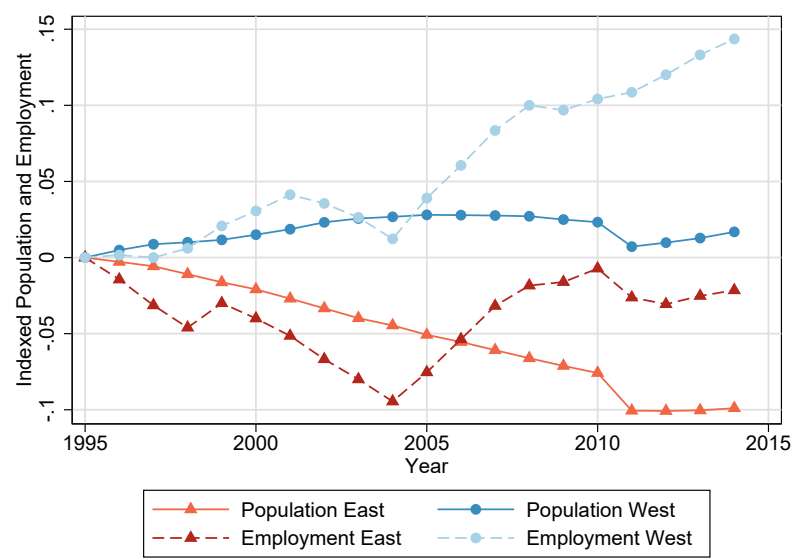

Note.- The figure shows population and employment in East and West Germany. Employment is measured relative to the working-age population. The jump in population between 2010 and 2011 arises from projection adjustments after the Population Census of 2011.

Source: German Federal Statistical Office.

Figure 5 further indicates substantial employment losses of around $10 \%$ in East Germany between 1995 and 2004. ${ }^{10}$ Since 2004, employment has risen steadily in East Germany. By 2014, East Germany has finally reached the employment levels it had in 1995. West Germany in contrast, saw few employment changes prior to 2004, but a substantial increase since then. By 2014, employment in West Germany is $15 \%$ higher than in 1995. In sum, the evidence suggests that Germany experienced large employment gains since 2004 - but West Germany has benefited from it even more than East Germany. The cause for this employment miracle is still debated: A prominent explanation attributes the employment growth to declining labor costs and wage moderation fueled by the decline of unions' bargaining power (Dustmann et al., 2014). Another argument points to the export industries as motor for net employment gains (Dauth et al., 2014). Finally, several authors have linked the growth in employment to the comprehensive labor market reforms (Hartz I-IV) that were implemented in Germany between 2003 and 2005 (see Krause and Uhlig, 2012; Launov and Wälde, 2013; Krebs and Scheffel, 2013; Burda and Seele, 2016; Hartung et al., 2018; Price, 2018). ${ }^{11}$ For the purpose of identifying the sources of wage inequality, it does not matter which of these channels drives employment growth. What is important here is whether higher inflows influence the observed wage distribution indirectly through changing workforce composition and earnings potential. We analyze the direct influence of unions and trade on the wage structure in

\footnotetext{
${ }^{10}$ Sizable employment losses occurred in the years between 1989 and 1994 when many companies in East Germany had to shut down (Insitut für Wirtschaftsforschung Halle, 2014).

${ }^{11}$ The reforms increased job finding rates (Krebs and Scheffel, 2013; Hartung et al., 2018; Price, 2018). These have been attributed to higher search efforts due to declining replacement rates in the UI system (Krebs and Scheffel, 2013), changes in firms' vacancy posting (Krause and Uhlig, 2012) or improved placements by local employment offices (Launov and Wälde, 2013). Jung and Kuhn (2014) provide evidence that separation rates also dropped after the labor market reforms.
} 
more detail in the next sections.

The evidence in figure 5 clearly demonstrates that we cannot ignore changes along the employment margin when studying the East German wage structure. The decline in East German employment before 2004 might compress wage inequality and overstate wage growth in East Germany, for instance, if those leaving the labor market earn lower wages than the average East German employee. The decline in population, in turn, might have the opposite effect as existing evidence suggests that outmigration was disproportionately higher among young people and the high-skilled (Hunt, 2006; Uhlig, 2008; Fuchs-Schündeln and Schündeln, 2009). The stark employment growth in both East and West Germany after 2005, in contrast, might reduce observed wage growth and overstate the rise in wage inequality if those entering the workforce earn below-average wages.

To better understand the nature of selection, we compare the characteristics of individuals leaving the East German labor market between 1995 and 2004 and those entering the East German labor market between 2004 and 2014 to the average East German worker. The top panel of table B5 in the appendix compares employed stayers (with a job in East Germany) between the 15th and 50th wage percentile and at the median wage to all leavers (who were employed in East Germany in year $t$, but not in $t+1$ ), and to the subgroup of leavers with a new job in West Germany. The latter category combines migrants from East to West and commuters who work in West Germany, but continue to live in East Germany. Leavers are older and more likely to be high-skilled than stayers, while outmigrants are younger and more skilled than stayers. In terms of wages, leavers including outmigrants are close to the median earner in 1995; by 2004, leavers perform worse than the median East German worker. Instead, leavers are located somewhere between the 15th and 50th percentile of the East German wage distribution by 2004. Hence, leavers become more negatively selected between 1995 and 2004, but never come from the very bottom (below the 15th percentile) of the East German wage distribution.

The bottom panel of table B5 compares entrants between 2004 and 2014 to employed workers. Here, we distinguish between all entrants (who do not have a record in $t$, but a social security record in $t+1$ ) and first-time entrants (who appear in the social security records for the first time). Entrants are of similar age and much more likely to be high-skilled than the typical employee (stayer) at the median or between the 15th and 50th percentile range. Not surprisingly, labor market entrants are much younger and less likely to be medium-skilled than stayers. On average, entrants have lower earnings than the median worker, but are located in the range between the 15th and 50th wage percentiles both in 2004 and $2014 .{ }^{12}$ Not surprisingly, first-time entrants have

\footnotetext{
${ }^{12}$ The evidence that entrants after 2004 have lower earnings capacity than the median earner, but do not come from the very bottom of the wage distribution is in line with Price (2018). He shows that individuals who found a new job after the Hartz IV reforms earned 4- $8 \%$ less than the average employee but found few wage effects overall because of shorter non-employment spells.
} 
the lowest earnings but improve their relative position over time. Overall, the consequences of the net employment losses between 1995 and 2004 on the East German wage structure are not clear as migrants are positively selected but other leavers negatively selected compared to stayers. In contrast, the individuals who found new jobs during the 2004-2014 period are negatively selected compared to stayers. As such, we would expect that selection into work overstates the rise in wage inequality after 2004 .

To assess the impact of selective entry and exit on the wage structure more formally, we impute missing wages using alternative assumptions on the earnings of leavers and entrants following the literature on the Black-White or gender wage gaps (see, e.g., Johnson et al., 2000, Chandra, 2003, and Neal, 2004, who study the Black-White wage gap; or Hunt, 2001, and Olivetti and Petrongolo, 2008, who analyze gender wage gaps). ${ }^{13}$ We thus define a new wage variable, which is equal to the observed wage $w_{i t}$ for employed workers and equal to an imputed wage $\tilde{w}_{i t}$ for observations with missing wages. Our first approach exploits the panel structure of our data to impute wages using an individual's past (for leavers) or future (for entrants) wage information. That imputation method assigns an imputed wage that is close to an individual's true earnings potential; yet, it only captures individuals who remain attached to the labor market. The second approach imputes wages based on observable characteristics (education, age and year). In effect, we assign the mean wage within each cell to individuals with missing wages belonging to the same education and age group in each year. This method will impute wages for many more individuals than the first method but will not capture differences in unobservables. Our third method uses the information from table B5 that leavers and entrants are, in terms of their earnings capacity and observable skills, located somewhere between the 15 th and 50 th percentiles of the wage distribution. To provide a lower bound of how selection affects the wage structure, we assign the median wage to the missing wage observations of leavers and entrants. As an upper bound, we assign a wage for entrants and leavers equal to workers at the 15 th percentile. The latter imputation method assumes some negative selection or sizable depreciation of human capital while un- or nonemployed. The resulting 85-50 and 50-15 wage gaps using the different imputation methods are shown in table $2 .{ }^{14}$ For leavers, we start in 1996 so we can impute wages from past employment spells. The top panel of table 2 shows that the 85-50 wage gap remains largely unaffected by accounting for leavers independent of the imputation method used. This result is not surprising as leavers come from the lower part of the wage distribution on average. It is somewhat more surprising that there is little effect on the 50-15 wage gap as well. The only exception is when we assign all leavers the wage of the 15 th percentile, which reduces the 50-15 wage gap by 0.07-0.09 log points (or about 20\%).

\footnotetext{
${ }^{13}$ Alternatively, one could use a control function approach to correct wages for selection along the employment margin. Unfortunately, a quasi-experimental setting being absent, it is difficult to identify an exclusion restriction that would affect job finding or employment probabilities but has no effect on the individual's earnings capacity.

${ }^{14}$ For West Germany, we present the same imputation procedures for leavers and entrants in table B3 in the Appendix.
} 
Table 2: Log Wage Gaps in East Germany after Imputation

\begin{tabular}{|c|c|c|c|c|}
\hline & \multicolumn{4}{|c|}{ Imputation of leavers' wages } \\
\hline & \multicolumn{2}{|c|}{1996} & \multicolumn{2}{|c|}{2004} \\
\hline & 50-15 Gap & 85-50 Gap & 50-15 Gap & 85-50 Gap \\
\hline No Imputation & 0.33 & 0.44 & 0.40 & 0.53 \\
\hline Carried-forward wages & 0.33 & 0.44 & 0.39 & 0.55 \\
\hline Imputation on observables & 0.33 & 0.41 & 0.40 & 0.51 \\
\hline Leaver wages set to 50 -pct. & 0.30 & 0.39 & 0.37 & 0.48 \\
\hline \multirow[t]{4}{*}{ Leaver wages set to 15 -pct. } & 0.26 & 0.46 & 0.31 & 0.57 \\
\hline & \multicolumn{4}{|c|}{ Imputation of entrants' wages } \\
\hline & \multicolumn{2}{|c|}{2004} & \multicolumn{2}{|c|}{2014} \\
\hline & 50-15 Gap & 85-50 Gap & 50-15 Gap & 85-50 Gap \\
\hline No Imputation & 0.40 & 0.53 & 0.41 & 0.58 \\
\hline Carried-backward wages & 0.41 & 0.54 & 0.40 & 0.59 \\
\hline Imputation on observables & 0.39 & 0.51 & 0.40 & 0.55 \\
\hline Entrant wages set to 50 -pct. & 0.37 & 0.49 & 0.38 & 0.54 \\
\hline Entrant wages set to 15 -pct. & 0.33 & 0.56 & 0.34 & 0.61 \\
\hline
\end{tabular}

Note.- The table shows 50-15 and 85-50 log wage gaps including individuals who have no full-time job spell next year (top panel); and the same wage gaps when the wages of entrants in the East German labor market are included. Carried-forward wages use the panel structure to impute wages; imputation on observables predicts missing wages based on education, age and year. The last two imputation methods set missing wages to the 50 th percentile or the 15 th percentile of employees in the particular year.

Source: 2\% SIAB Sample for East German male full-time workers between 20 and 62 years of age 
For entrants, the bottom panel of table 2, we find very similar effects. The imputed 85-50 wage gaps are a bit lower or higher than the observed 85-50 wage gap but the difference is very small. For the 50-15 wage gap, we find deviations of $0.07 \mathrm{log}$ points (or about $35 \%$ ) when we assign entrants the 15th percentile wage of stayers for non-employment spells prior to actual entry. In sum, selection along the employment margin, if anything, overstates the growth in wage inequality at the bottom of the distribution. Accounting for selective exit and entry along the employment margin cannot explain the fast growth in East German wage inequality at the top of the distribution until 2009.

\subsection{Changes in the College Premium}

While selective entry and exit into the labor market and changes the composition of the labor force alone do only have minor direct effects on the East German wage structure, there still might be indirect effects through changes in skill prices. For instance, even if the large out-migration of high-skilled individuals from East Germany in the 1990s did only have small effects on the work-force composition, it might have led to faster increase in the skill premium in East Germany.

Therefore, we next explore the role of wage differentials between educational groups for the evolution of inequality in East Germany.

As increasing skill-prices could be a candidate to explain the rise in inequality at the top, we will focus on the college premium and abstract from differences between the low and middleskilled. ${ }^{15}$ We obtain college premiums from separate regressions of imputed log wages in East or West Germany on education and age categories as well as a full set of interactions for each year from 1995 to 2017. We then compute the wage differentials between college-educated and less-skilled individuals using the average education and age composition of the workforce over the whole period (calculated separately for East and West Germany). Hence, changes in the demographic composition of the workforce through demographic aging, for instance, cannot explain the observed changes in the college premiums. The left panel of figure 6 shows that the skill premium for collegeeducated workers has been rising in both East and West Germany until 2010 and then declined sharply thereafter. Even more importantly, the college premium rises much faster in East Germany than in the West: while the college premiums are similar until 2000, the East German college premium for the high-skilled exceeds the West German one by around 5 percentage points in 2010

\footnotetext{
${ }^{15}$ This simplification is also reasonable since only a very small share of the East German workforce does not have high school degree even in 1995. Nevertheless we present the skill-premium between middle and low skilled workers in figure B2 in the appendix. The medium-low skill premium is much lower in East Germany than in West Germany, converges toward the West German one until around 2009 and then declines again thereafter. The relative supply of medium-skilled workers, which is computed in a corresponding fashion to the relative supply of college educated workers, is higher in East Germany, but grows at a similar rate in East and West Germany between 1995 and 2014. The East German pattern is consistent with a positive relative demand shift for medium-skilled workers until 2008. The development after 2008 is consistent with the evidence in the next section that sector-specific minimum wages, by pushing up wages at the bottom of the distribution, reduced the skill premium between medium- to low-skilled workers in East Germany.
} 
and 2014. The higher growth in East Germany suggests one of two things: a stronger growth in the demand for college-educated workers or a slower growth in the supply of college-educated workers in East Germany compared to West Germany.

The evidence in table 1 suggests that the college-educated share has expanded more slowly in the East than in the West. To capture the influence of growth in relative supply on the college premium, we calculate relative skill supplies. We first compute average wages in 1995 for each of the 24 education-age cells (three education and eight age groups) normalized by the average wage of the reference group (37-40 years-old, medium-skilled individuals). ${ }^{16}$ We choose the start of our sample period in 1995 as reference year in order to abstract from potential demand side shifts in later years. To calculate the labor supply of an age-education cell, we then take the total number of employees in each of the 24 education-age cells in year $t$ times the normalized 1995 wage. The relative supply of college to non-college labor in a given year measured in efficiency unit is then calculated as the sum of college-educated employees over all age groups in that year divided by the sum of employees with a lower educational degree across all age groups in the same year.

Figure 6: College Premiums and Relative Supplies
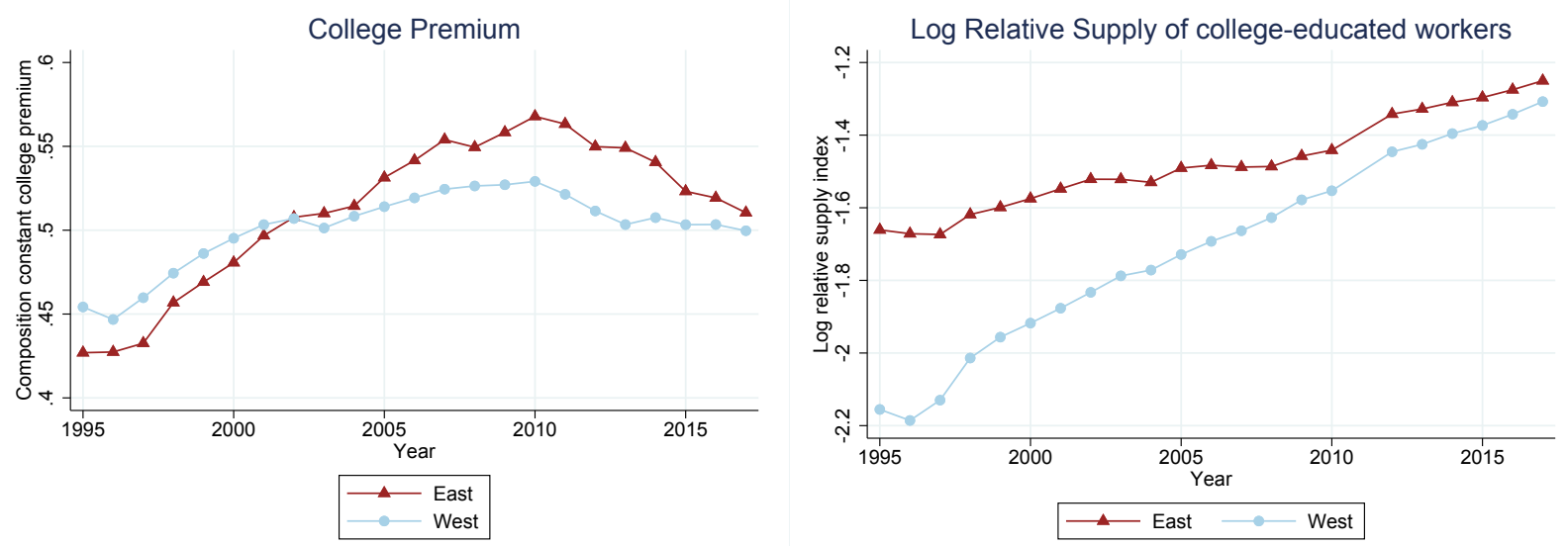

Note.- The left panel plots the age-adjusted college premium for men in East and West Germany. The right panel plots the relative skill supply of college-educated workers compared to non-college workers measured in efficiency units.

Source: $2 \%$ SIAB Sample for male full-time workers between 20 and 62 years of age.

The right panel of figure 6 shows that the relative supply of college-educated workers has been rising in East and West Germany throughout the 1995-2014 period. As the college premium increased in both regions until 2010 as well (see left panel of figure 6), the relative labor demand for college-educated workers must have increased even faster than the their supply. Yet, the growth in the relative supply of college-educated workers has been much slower in East Germany. After 2010, the relative supply continues to increase in East and West but the college premium actually declines pointing to a slowdown in the demand for high-skilled workers.

\footnotetext{
${ }^{16}$ The results do not depend on the particular choice of the reference group. This skill supply measure is similar to an efficiency unit representation of the relative supply of college and non-college labor as in e.g. Autor et al. (2008).
} 
The striking difference in the evolution of college premiums in East and West Germany up to 2010, raises the question, whether high out-migration rates of college-educated employees and those planning to obtain a university education prior to 2010 have led to the slower supply growth and the faster increase of the college premium in the East. And, to what extent did this divergent development contribute to the greater increase in wage inequality at the top end of the wage distribution in the East? To address these questions, we follow Card and Lemieux (2001) and use a CES production function approach to assess, the relation between out-migration, relative supply changes and college premiums.

In this framework the labor of workers with a college degree $\left(C_{t}\right)$ and all other labor in East Germany $\left(H_{t}\right)$ are the only inputs in a CES production function.

$$
Y_{t}=\left(\theta_{c t} C_{t}^{\rho}+\theta_{h t} H_{t}{ }^{\rho}\right)^{\frac{1}{\rho}}
$$

where $-\inf <\rho \leq 1$ is a function of the elasticity of substitution between college and non-college labor $\left(\rho=1-1 / \sigma_{E}\right)$. The shares of different types of labor are represented by the technology parameters $\theta_{c t}$ and $\theta_{h t}$. These parameters reflect, among other things, any changes in production through technology or labor market institutions other than the aggregate labor inputs modeled in the production function. Moreover, labor in each skill group is a CES-aggregate of the labor of workers in $j$ different age groups.

$$
H_{t}=\left[\sum_{j}\left(\alpha_{j} H_{j t}\right)\right]^{\frac{1}{\eta}} \quad C_{t}=\left[\sum_{j}\left(\beta_{j} C_{j t}\right)\right]^{\frac{1}{\eta}}
$$

where $-\inf <\eta \leq 1$ depends on the elasticity of substitution between age groups $\left(\eta=1-1 / \sigma_{A}\right)$ and $\alpha_{j}$ and $\beta_{j}$ are relative efficiency parameters for the different age-groups that are fixed over time.

Assuming that labor is paid its marginal product, we obtain

$$
\log \left(\frac{w_{j t}^{C}}{w_{j t}^{H}}\right)=\log \left(\frac{\theta_{c t}}{\theta_{h t}}\right)+\log \left(\frac{\alpha_{j}}{\beta_{j}}\right)-\left(\frac{1}{\sigma_{E}}\right) \log \left(\frac{C_{t}}{H_{t}}\right)-\left(\frac{1}{\sigma_{A}}\right)\left[\log \left(\frac{C_{j t}}{H_{j t}}\right)-\log \left(\frac{C_{t}}{H_{t}}\right)\right]
$$

Equations (3) is estimated in three steps. We first estimate $\sigma_{A}$ from a regression of the agespecific college premiums on age-specific relative supplies, age-group dummies and a time trend

$$
\log \left(\frac{C_{j t}}{H_{j t}}\right)=b_{j}+d_{t}-\left(\frac{1}{\sigma_{A}}\right) \log \left(\frac{C_{j t}}{H_{j t}}\right)+\varepsilon_{j t}
$$

Next, we rearrange the marginal productivities for both skill groups and plugin our estimate of $\sigma_{A}$ 
from the first step to estimate the efficiency parameters $\alpha_{j}$ and $\beta_{j}$

$$
\begin{aligned}
\log \left(w_{j t}^{H}\right)+\frac{1}{\sigma_{A}} H_{j t} & =\log \left(\alpha_{j}\right)+\log \left(\theta_{h t} H_{t}^{\rho-\eta}\left[\theta_{c t} C_{t}^{\rho}+\theta_{h t} H_{t}^{\rho}\right]^{\frac{1}{\rho}-1}\right) \\
\log \left(w_{j t}^{C}\right)+\frac{1}{\sigma_{A}} C_{j t} & =\log \left(\beta_{j}\right)+\log \left(\theta_{c t} C_{t}^{\rho-\eta}\left[\theta_{c t} C_{t}^{\rho}+\theta_{h t} H_{t}{ }^{\rho}\right]^{\frac{1}{\rho}-1}\right),
\end{aligned}
$$

where the efficiency parameters in the first term are represented in the regression as age-groupdummies and the second term is absorbed by the time trend. Using our estimates of $\sigma_{A}, \alpha_{j}$ and $\beta_{j}$, allows us to directly estimate equation (3).

This yields estimates of $q_{A}=9.29$ and $q_{E}=10.81$ for East Germany, which is in a similar range than the estimated elasticities for the substitutabilties across skill and age-groups in Card and Lemieux (2001). This suggests, that the slower growth in relative supply at least partially explains the slower increase in the college premium.

Beyond that, we can use our estimates of the elasticity of substitution between college and non-college work and the substitutability between age groups to calculate counterfactual college premiums for a scenario without out-migration from the East. In order to do this, we use data on age-specific out-migration rates from the federal statistical office to compute what share of each birth-cohort left the East-German Labor market in each year between 1991 and 2017. By combining this information with data on labor supply from social security records, we can calculate the cumulative amount of out-migration in each age group over time and thus also include people who left in earlier years in their appropriate age groups over time. To get an upper bound for the maximal effect of out-migration on the college premium we compute an extreme counterfactual, where we assume that all out-migrants would eventually attain a college degree. We compute relative supply of college to non-college labor for this counterfactual and use our estimates of equation (3) to compute counterfactual skill premiums for each year in our sample.

We plot this counterfactual college premium in the left panel of figure 7 and compare it to the college premium in East and West Germany. Under this extreme out-migration counterfactual the college premium in East Germany would have increased drastically slower and would have remained below the level of the West-German skill premium in 2010. However, even in this extreme scenario the East German college premium still increases over time, suggesting that demand forces might play an important role for skill prices. 
Figure 7: Counterfactual College Premiums
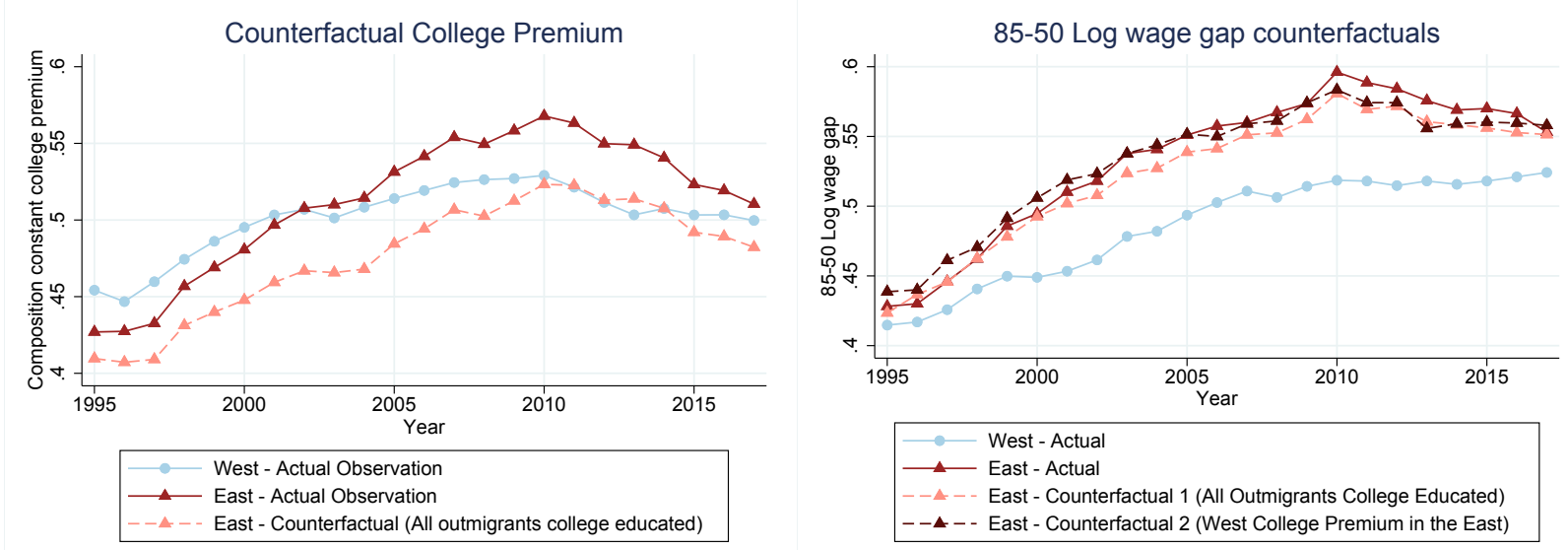

NoTE.- The left panel plots a counterfactual skill premium for a scenario, where all East German outmigrants are assumed to be college educated and are added back to East German labor force. The right panel plots the 85-50 log wage for Eats and West Germany and two counterfactual scenarios for the East assuming different college-premiums.

Source: $2 \%$ SIAB Sample for male full-time workers between 20 and 62 years of age.

While our results from our CES production function approach and our counterfactual scenario on the role of out-migration suggest that the slower growth in college-educated labor is an important driver for the faster rise in the college premium in East Germany, it is no yet clear to what extent this development contributed to the faster increase in top-end inequality. Therefore, we compute the 85-50 wage gap for two counterfactual scenarios. The first of these is a scenario where we replace actual the East German college premium with our zero-outmigration counterfactual. Moreover, we swap out the East German college premium with the West German college premium in the second scenario. While the first scenario gives us an upper bound for the effects of a lower college premium on top-level wage inequality, the second scenario gives us the maximal change in wage-inequality in East Germany if college premiums had followed the same trajectory as in th West. We plot counterfactual 80-50 wage gaps as well as the actual 80-50 wage gaps for East and West Germany in the right panel of figure 7 .

The two counterfactual scenarios closely follow the actual development of the 85-50 wage gap in East Germany, suggesting that the faster increase in the college-premiums in East Germany had only small effects on the faster increase in top-end-wage inequality. Overall changes on the supply side can only explain a small part of the different development in wage inequality in East and West Germany.

We next turn to the question how labor market institutions influenced wage inequality in East Germany. 


\section{The Role of Labor Market Institutions}

How might labor market institutions help to explain the faster growth in wage inequality in East Germany prior to 2010 and its reversal since 2010? Legally, labor market institutions do not differ between East and West Germany. However, because the institutions operate in labor markets that differ in their underlying structure, they might have different consequences for wage inequality. During our sample period, several industries have introduced sector-specific minimum wages. Furthermore, Germany, like other countries, has experienced a significant decline in union coverage over time. We explore the contribution of each of these factors on the wage structure in turn.

\subsection{Decline in Unionion Coverage}

We first assess whether unions and their decline play a role for the rising wage inequality in East Germany until 2010. Several studies have pointed to the contribution of de-unionization to the widening wage distribution in the United States (e.g. DiNardo et al., 1996; Card et al., 2004; Farber et al., 2018) and in West Germany (Dustmann et al., 2009; Antonczyk et al., 2010; Fitzenberger et al., 2013).

In Germany, trade unions can negotiate collective bargaining agreements either with employer associations at the industry and regional level or with individual firms. If a trade union has reached an agreement with an employers' association, the negotiated result applies to all employees of establishments that are members of the employers' association, irrespective of whether an employee is member of the union or not. While collective bargaining agreements between unions and employers' associations cover whole industries, bilateral agreements between unions and firm apply only to employees of the particular firm.

To assess the role of unions, we use the matched employer-employee data (LIAB) combining plant-level information on the type of bargaining agreement with social security records of all workers in that plant. Figure 8 shows a sharp decline in trade union coverage until 2005 and a much more modest decline since then. In West Germany, the proportion of employees covered by an industry-wide collective agreement fell from $76 \%$ in 1996 to $63 \%$ in 2005 and to $57 \%$ in 2014 . Collective bargaining declined even more dramatically in East Germany: the share of workers covered by an industry-level trade union agreement decreased from 59\% in 1996 to $40 \%$ in 2005 and to $36 \%$ in 2014 . The decline cannot be explained by inter-industry shifts in employment; rather, union coverage declines in all industries - those with traditionally high coverage rates like manufacturing and those without like services (Antonczyk et al., 2010). 
Figure 8: Collective Bargaining Coverage
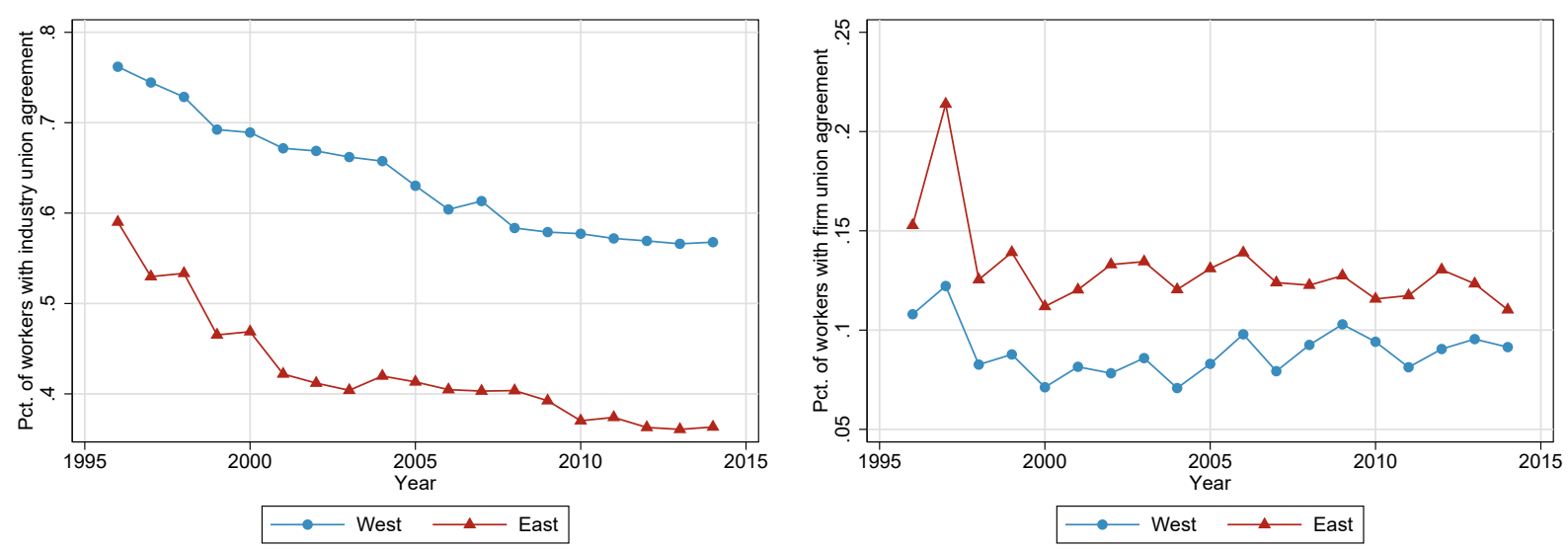

Note.- The figures display the share of workers covered by an industry-level (left panel) or firm-level (right panel) collective bargaining agreement.

Source: LIAB Data

The right panel of figure 8 shows that firm-level agreements are generally rare, but more common in East Germany than in West Germany. The share of workers covered by firm-level agreements declines from $10-15 \%$ to about $8-12 \%$ since 2000 and remained roughly stable since. The patterns in figure 8 suggest that the decline in union coverage might have its strongest impact on wage inequality prior to 2005 - and with a potentially stronger effect in East Germany. To quantify how declining union coverage rates influence the East German wage structure, we again use inverse probability weighting (DiNardo et al., 1996). We hereby focus on the period from 1996, the first year in the LIAB data, and 2005, as union coverage rates leveled off in both East and West Germany thereafter. To construct the counterfactual, we reweigh the 2005 wage distribution to reflect the 1996 level of union coverage. We use a flexible specification including all possible interactions between the three states of collective bargaining (sector, firm or none), eight age and three education groups to estimate the propensity score. Based on the propensity score, we then compute the weights. Note that the chosen specification accounts for changes in workforce composition as well as differential changes in union coverage rates across education and age groups. It is also important to stress that the reweighting approach is flexible enough to allow for differential union wage premiums at the bottom and top of the wage distribution. As before, the approach abstracts from general equilibrium effects assuming that these union wage premiums are unaffected by declining union coverage rates. As existing evidence suggests that the causal effect of union coverage on wages is close to zero, this assumption seems innocuous. ${ }^{17}$ Figure 9 shows the observed real wage growth between 1996 and 2005 (the blue line) and the reweighted counterfactual using the 1996 union coverage rates (the dashed red line).

\footnotetext{
${ }^{17}$ OLS regressions indicate a union wage premium of about 4-6\% in Germany, while the evidence using instrumental variable regressions suggest no return (Antonczyk et al., 2011).
} 
Figure 9: Unionization and Wage Inequality
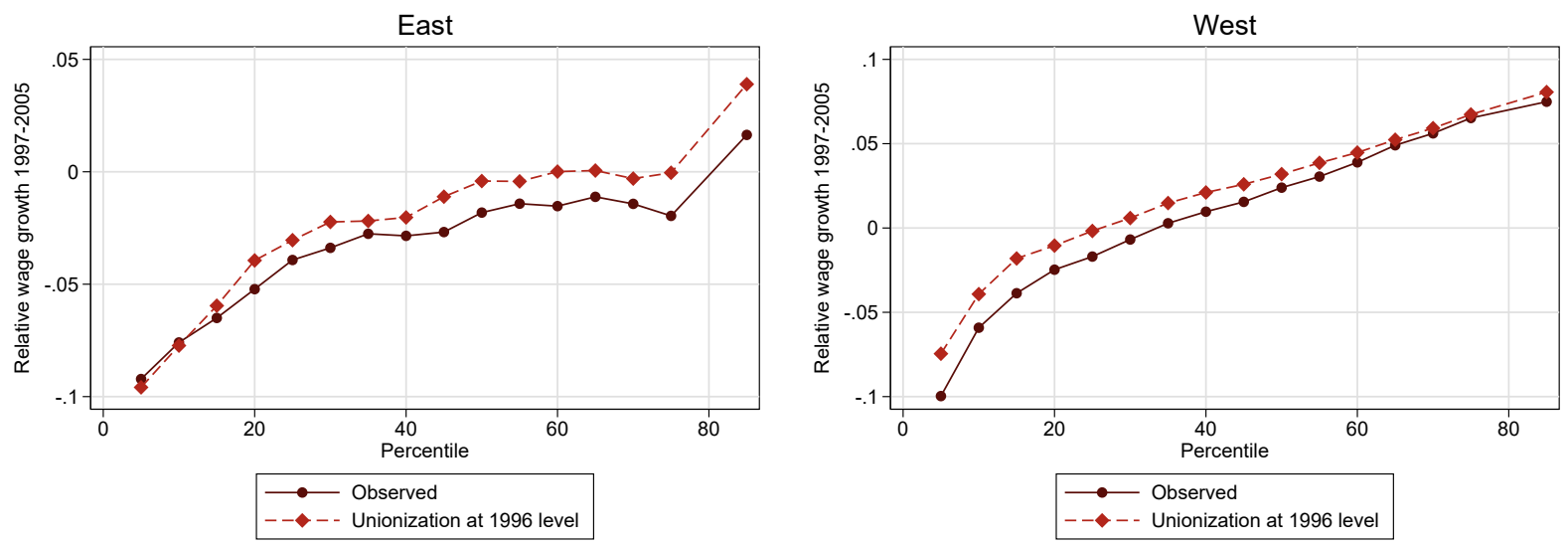

Note.- The figures compare the actual change in log real wages between 1996 and 2005 with a scenario where unionization are adjusted to their 1996 level for both East Germany (left panel) and West Germany (right panel).

Source: LIAB Data

The panel for East Germany on the left-hand side reveals a surprising pattern: higher union coverage rates in 2005 would not have raised wages at the bottom of the wage distribution. Quite on the contrary: The union coverage effects are positive above the 20th percentile and strongest in the middle part of the East German wage distribution. In sharp contrast, the pattern is the exact opposite in West Germany: Higher union coverage in West Germany would have raised wages at the bottom of the wage distribution. The effect on wage inequality declines above the 20th percentile and becomes zero for wages above the 60 th percentile. Why would low-wage workers

Table 3: Union Coverage by Wage Percentiles

\begin{tabular}{|c|c|c|c|c|c|c|c|c|}
\hline \multicolumn{9}{|c|}{ Share of workers without union coverage } \\
\hline & \multicolumn{4}{|c|}{ East } & \multicolumn{4}{|c|}{ West } \\
\hline & Below 15 & 15 to 50 & 50 to 85 & Above 85 & Below 15 & 15 to 50 & 50 to 85 & Above 85 \\
\hline 1996 & $46.81 \%$ & $23.89 \%$ & $13.80 \%$ & $14.49 \%$ & $18.03 \%$ & $9.41 \%$ & $12.56 \%$ & $13.23 \%$ \\
\hline 2005 & $65.74 \%$ & $43.10 \%$ & $29.37 \%$ & $29.89 \%$ & $38.27 \%$ & $21.45 \%$ & $24.54 \%$ & $27.10 \%$ \\
\hline
\end{tabular}

Note.- The table shows the share of the share of workers without any bargaining agreement for workers earning below the 15 th percentile ('Below 15'), workers earning between the 15 th and 50 th percentiles (' 15 to 50 '), workers earning between the 50 th and 85 th percentiles (' 50 to $85^{\prime}$ ) and workers earning above the 85 th percentile ('Above 85').

Source: LIAB data for male full-time workers between the ages of 20 and 62 .

in East Germany not benefit from the higher union coverage rates that prevailed in 1996? One potential explanation is that coverage rates are lower at the bottom of the wage distribution than in the middle or top of the wage distribution. Table 3 shows union coverage rates in 1996 and 2005 for workers at different percentiles of the wage distribution. The most striking feature emerging from table 3 is that union coverage rates are much lower for East German workers earning below the median wage than West German workers. Almost half of East German workers with wages below the 15th percentile are not covered by any collective bargaining agreement already in 1996 . 
By 2005, the share without coverage has increased to two-thirds of all employees with wages below the 15 th percentile.

To the extent that the weaker coverage translates into a worse bargaining position during wage negotiations, the decline of union representation had little effect on the bottom of the wage distribution in East Germany. Instead, the decline of unions muted wages in the middle and upper part of the distribution (see also DiNardo et al., 1996, for similar evidence). If coverage rates had remained at their 1996 level, wage inequality at the top would have increased even more. Overall then, unions play only a limited role in explaining the evolution of wage inequality in the East - in sharp contrast to West Germany where the decline of unions contributed to rising wage inequality (see also Dustmann et al., 2009).

\subsection{Sectoral Minimum Wages}

Sector-specific minimum wages were first introduced in Germany in 1997. Since 1996, the federal government could declare collective bargaining agreements as binding for all workers in an industry irrespective of union coverage. The main intention of the law was to protect domestic employees and employers from foreign competition by defining legal standards, among them a minimum wage. While the first minimum wages covered relatively small industries, several large sectors, like temporary agency work, building cleaners or care and nursing, introduced minimum wages between 2007 and $2013 .{ }^{18}$

We obtain data on minimum hourly wages listed in collective bargaining agreements from the Federal Statistical Office (German Federal Statistical Office, 2017). In 2014, the hourly minimum wage ranges from 7.86 Euros per hour in temporary work to 11.92 Euros per hour in mining. The minimum wages apply to the whole country in about half of the industries, while they are lower in East Germany in the remaining 50\%. The maximum differential in minimum wages for the same industry between East and West is 15\% for building cleaners. As wage levels are almost 30\% lower in East Germany (see table 2), minimum wages have been more binding in the East German labor market. Sector-specific minimum wages are thus a promising candidate for explaining the reversal in wage inequality, especially in East Germany, since 2009. We restrict our analysis to the period from 2008 to 2014 as most sector-specific minimum wages were introduced over this period. ${ }^{19}$ We convert hourly values into monthly wages using 30 working hours per week for our sample of full-time workers. ${ }^{20}$

\footnotetext{
${ }^{18}$ See appendix A for a list of the industries. A national minimum wage covering all sectors was introduced only after the end of our sample period on January 1,2015 .

${ }^{19}$ As minimum wage industries are identified at the 5-digit level only, the restriction to the 2008-2014 period also help us avoid inconsistencies due to structural breaks in the industry classification in 1993, 2003 and 2008.

${ }^{20}$ Assuming a 30-hour workweek provides a conservative estimate of the share of affected workers if the typical workweek is above 30 hours.
} 
Figure 10: Sectoral Minimum Wages: Share of Affected Workers
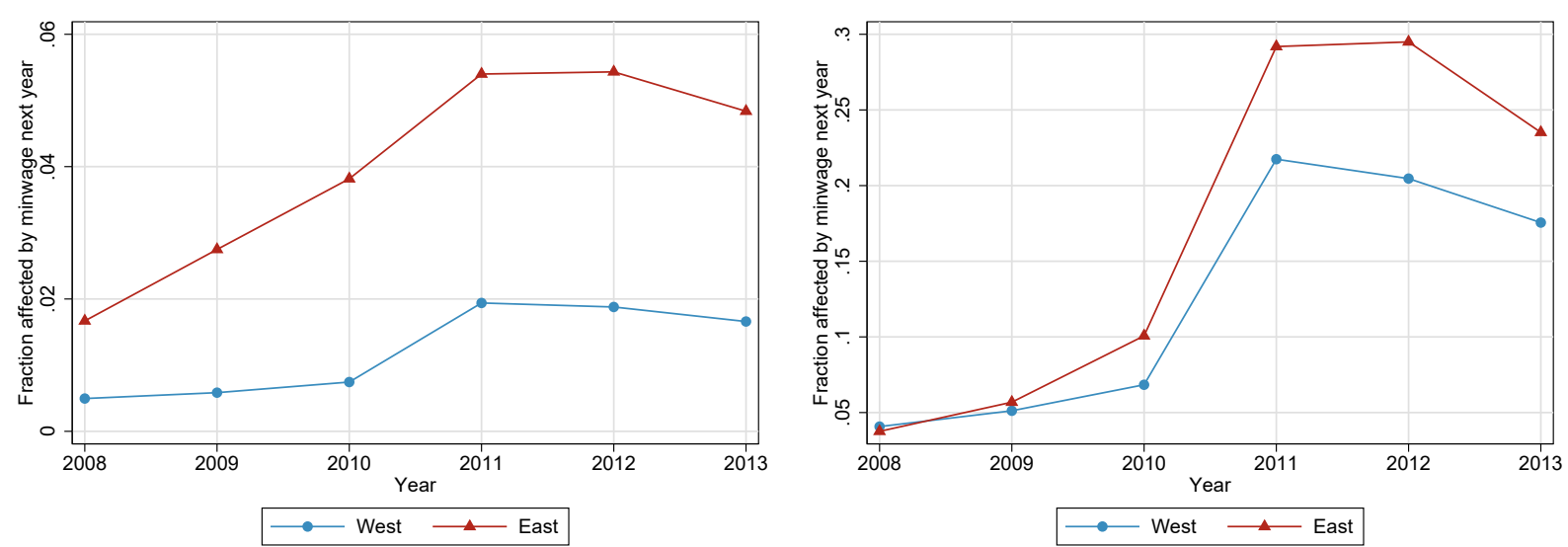

Note.- The figures show the share of workers potentially affected by a minimum wage, i.e. with wages below the minimum wage in their industry in the following year. The left panel refers to all full-time workers, the right panel includes wage earners up to the 15 th percentile only.

Source: $2 \%$ SIAB Sample for male full-time workers between 20 and 62 years of age.

Figure 10 plots the fraction of workers whose wage is below next year's minimum wage in their respective industry relative to all workers (in the left panel) and workers with wages up to the 15th percentile (in the right panel). The share of workers potentially affected by sector-specific minimum wages is much higher in East Germany (6\% of all workers by 2012) than in West Germany (only $2 \%$ of all workers) reflecting the lower wage levels in East Germany. Compared to low-wage earners the share of East German workers affected by minimum wages even triples from around $10 \%$ to $30 \%$ between 2008 and 2012 .

To explore the distributional effect of sector-specific minimum wages, figure 11 plots the wage distributions in East Germany (in 2008 and 2014) separately for all industries with a sector-specific minimum wage (left panel) and for all other industries (right panel). The most striking feature of figure 11 is that there is a noticeable shift to the right at the bottom of the wage distribution in industries with a minimum wage. In contrast, the wage distribution is unchanged for all other industries. 
Figure 11: Wage Distributions in Industries with and without Minimum Wages
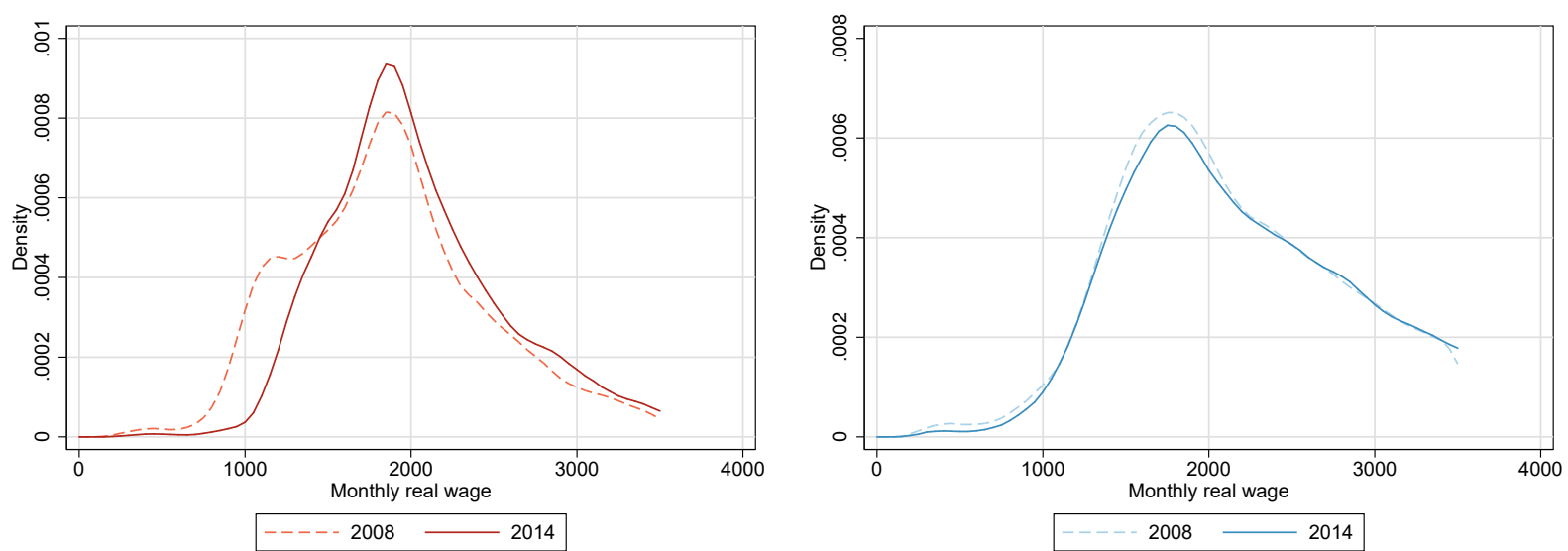

Note.- The figures plot the wage distributions in East Germany for industries with a sector-specific minimum wage (left panel) and all other industries (right panel) in 2008 and 2014. Monthly wages above 3500 Euros are omitted for better visibility.

Source: $2 \%$ SIAB Sample for male full-time workers between 20 and 62 years of age

Figure 11 indicates that sector-specific minimum wages are a good candidate to explain the decline in inequality at the lower tail in East Germany. To substantiate this claim, we again use the reweighting method to calculate counterfactual wage distributions for 2014 if sector-specific minimum wages had not been introduced. For industries without a sector-specific minimum wage, we use the actual wage distribution of that industry in 2014. For industries with a sector-specific minimum wage, we use the actual wage distribution above the minimum wage and the 2008 distribution for wages below the minimum wage. Our decomposition imposes four assumptions: first, the method abstracts from spillover effects on other industries, i.e. the adoption of minimum wages in one industry does not affect wages in other industries. If wages in other industries were pushed up, however, we would underestimate the contribution of minimum wages to wage growth. Under the assumption of no cross-industry spillovers, we can use the actual wage distribution in 2014 for industries without a minimum wage. The counterfactual wage density for 2014 is then simply the sum of the counterfactual densities for each minimum wage industry and the actual density of all industries without a minimum wage evaluated at 2014 industry shares $\phi_{i}$ :

$$
f\left(w \mid x, t=14, m_{08}\right)=\sum_{i=1}^{I} \phi_{i} f_{i}\left(x, t=14, m_{08}\right)
$$

We further assume that there are no spillovers to wages above the respective minimum wage in a covered industry. ${ }^{21}$ Then, the counterfactual 2014 industry distribution is identical to the respective actual distribution for wages above the respective minimum wage:

$$
\mathbb{1}\left(w>m_{14}\right) f_{i}\left(x, t=14, m_{08}\right)=\mathbb{1}\left(w>m_{14}\right) f_{i}\left(x, t=14, m_{14}\right)
$$

\footnotetext{
${ }^{21}$ While Autor et al. (2016b) find evidence for some spillover effects in the United States, they cannot rule out that these are due to misreporting.
} 
The available evidence suggests some positive spillover on wage earners above the minimum wage in selected industries (see Aretz et al., 2013, for evidence on the roofing industry). In that case, we underestimate the contribution of minimum wages to overall wage growth. A third assumption is that the counterfactual wage densities in 2014 , which would have emerged without minimum wages (or minimum wages set at their 2008 level), are proportional to the conditional wage densities in 2008. Hence,

$$
\mathbb{1}\left(w \leq m_{14}\right) f_{i}\left(x, t=14, m_{08}\right)=\psi\left(x, m_{14}\right) \mathbb{1}\left(w \leq m_{14}\right) f_{i}\left(x, t=08, m_{14}\right),
$$

where $\psi\left(x, m_{14}\right)$ is the inverse probability weight. The weight is computed from the propensity score that an observation is from the year 2014 (rather than 2008) using three education, eight age groups and all interactions as predictors of the propensity score.

Finally, we abstract from negative employment effects of minimum wages. If individuals displaced in a minimum wage industry earn lower wages in a different industry, we would observe a shift to the left, which would reduce the contribution of minimum wages to the decline in wage inequality after 2009. Given that existing evaluations of the sector-specific minimum wages have found few disemployment effects, this assumptions seems again of minor concern (see Fitzenberger and Doerr, 2016, for an overview). Based on these four assumptions, we compute the counter-

Table 4: Minimum Wage Counterfactual for 2014

\begin{tabular}{lccccccc}
\hline & 2008 & & 2014 & & \multicolumn{2}{c}{ Change from 2008 to 2014 } \\
& Actual & & Actual & Counterfactual & & Actual & Counterfactual \\
\cline { 2 - 3 } \cline { 7 - 8 } 10-percentile & 1325 & & 1475 & 1400 & & $11.3 \%$ & $5.7 \%$ \\
15-percentile & 1468 & & 1594 & 1550 & & $8.6 \%$ & $5.6 \%$ \\
50-percentile & 2222 & & 2371 & 2350 & & $6.7 \%$ & $5.7 \%$ \\
50-15 Log Wage Gap & 0.415 & 0.397 & 0.416 & & -0.018 & 0.001 \\
\hline
\end{tabular}

factual wage density for 2014 from separate kernel density estimates for each industry in East Germany for 2008 and 2014. We then integrate the estimated counterfactual density to a CDF and use its inverse to obtain estimates for the counterfactual wages at the median and the 10th or 15th percentiles. We present the actual percentiles in 2008 and 2014 together with the estimated counterfactual wages in table 4. In the counterfactual scenario, East German wage growth at the 10th percentile would have been $50 \%$, wage growth at the 15 th percentile would still have been $35 \%$ lower between 2008 and 2014. Even at the median, wage growth would have been lower without sector-specific minimum wages. ${ }^{22}$ Sector-specific minimum wages therefore account for a sizable

\footnotetext{
${ }^{22}$ In West Germany, wage growth between 2008 and 2014 is overall much lower: only $4 \%$ at the 10 th percentile and between 2.7-3.6\% at the 15th and 50th percentiles, respectively. Using the same decomposition as for East Germany, we find that sector-specific minimum wages contribute a similar share to wage growth in the lower tail: sector-specific minimum wages account for the majority of the modest wage gains at the 10th and 15th percentiles but play no role for median wages.
} 
share of wage growth at the bottom of the wage distribution since 2009. Moreover, the last row of table 4 shows that the adoption of sector-specific minimum wages can explain all of the decline in East German wage inequality and the leveling of West German wage inequality since 2009.

\section{The Labor Demand Side}

While sector-specific minimum wages can account for the turnaround in wage inequality in recent years, the fast rise in East German wage inequality, especially at the top, prior to 2009 remains unexplained. Our next step is thus to identify the type of demand-side changes that account for the growth in the 85-50 wage gap. To provide some guidance about the potential forces, figure 12 plots several estimates of the 85-50 wage gap: the raw wage gap, the wage gap after taking out observable skills (education, age and their full interaction), the wage gap after adding 3-digit industry fixed effects in addition to the skill variables; and finally, the wage gap after accounting for 3-digit occupation fixed effects in addition to the skill variables.

In East Germany (shown in the left panel), 30\% (0.05/0.17) of the increase in the 85-50 wage gap between 1995 and 2009 is explained by wage differentials between skills. In contrast, observable skills cannot explain any of the rise in top wage inequality in West Germany (shown in the right panel). Industries play an important role in explaining the rise of residual wage inequality at the top. In East Germany, inter-industry wage differentials (within skill groups) account for about $35 \%(0.06 / 0.17)$ of the rise in top wage inequality; in West Germany, the contribution is with $30 \%$ $(0.03 / 0.10)$ only slightly lower. Taken together, wage differentials between observable skills and industries account for $65 \%$ of the increase in East German wage inequality at the top. In West Germany, in contrast, $70 \%$ of the rise in top wage inequality occurs within skill and industries.

Figure 12: Raw and Residual 85-50 Wage Gaps
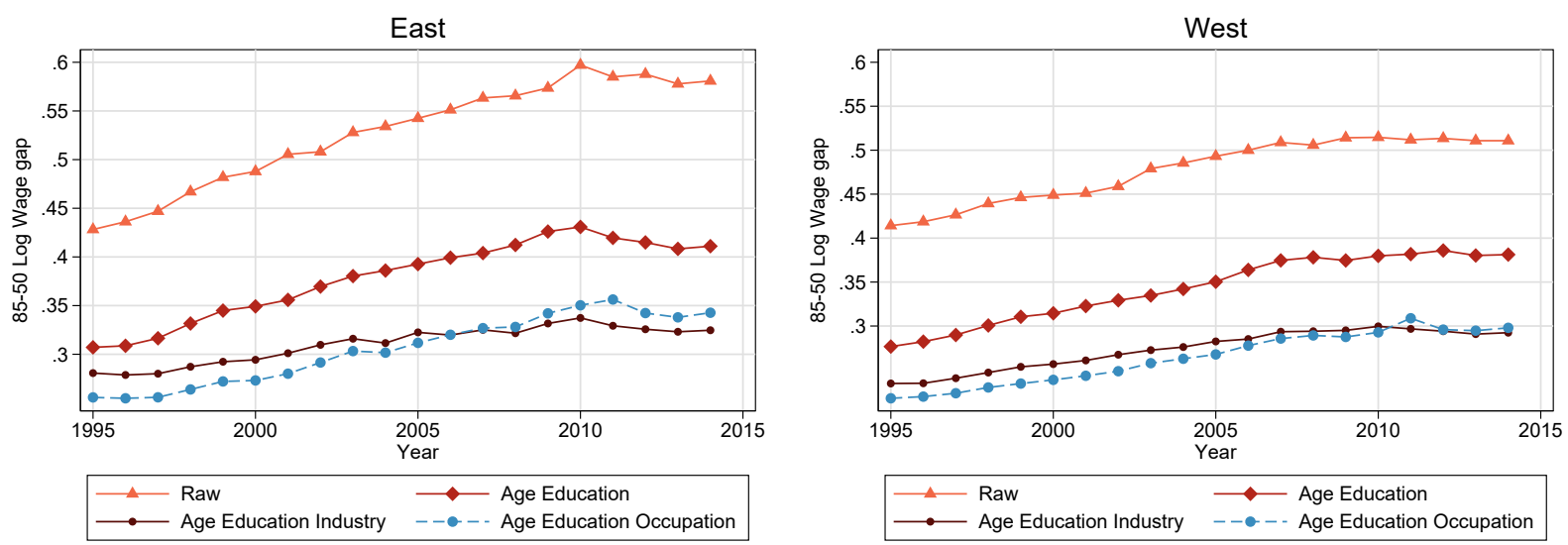

Note.- The figures show the raw 85-50 wage gap, the residual wage gap (three education, eight age groups and all interactions estimated separately in each year); the residual wage gap after accounting for 3-digit industries; and the residual wage gap after controlling for 3-digit occupations.

Source: $2 \%$ SIAB Sample for male full-time workers between 20 and 62 years of age. 


\subsection{Polarization and Routinization}

While the demand for skilled, and esp. college-educated labor has been rising, a substantial share of the rise in top wage inequality in figure 12 occurs within education and age groups. Several authors have argued that technological change is no longer skill-biased in favor of highly educated workers (Autor and Dorn, 2013; Goos et al., 2009, 2014). Rather, technological change has increasingly automated routine tasks, which are easily codifiable and repetitive. As routine tasks are typically performed in the middle of the skill distribution, routine-replacing technological change reduces employment and possibly wages in the middle of the skill distribution. Employment and possibly wages rise, in turn, at the top, where workers perform complementary, non-routine tasks, and at the bottom, where workers perform manual and interactive tasks - resulting in a polarization of the wage distribution.

To assess the role of routine-replacing technological change for top wage inequality, we first track the task content of occupations along the skill distribution. To this end we use task data from the 1997/98 wave of the Qualification and Career Survey (BiBB), which has been previously analyzed by Spitz-Oener (2006), Dustmann et al. (2009) and Gathmann and Schönberg (2010). We classify tasks into analytic, interactive, non-routine manual and routine tasks and calculate separate measures for East and West Germany. ${ }^{23}$ Sorting occupations by their experience-adjusted median wage in 1995 and dividing them into equal-sized skill groups, we plot the smoothed task intensity for the different tasks in figure B3. In East Germany, routine tasks are important between the 10th and 50th percentiles of the wage distribution; in West Germany, they are important for all occupations up to the 60th percentile. Routine tasks are least important at the top of the skill distribution in both parts of the country. Analytical skills, in turn, increase, while manual tasks decrease monotonically across the skill distribution. Interactive tasks are highest at the top and lowest in the middle of the skill distribution.

If labor demand for routine tasks declines, but increases for non-routine manual and analytical tasks, we should observe employment gains at the top and employment losses at the lower and middle part of the skill distribution. We next plot smoothed changes in employment for each skill percentile (defined by the experience-adjusted median wage of an occupation in 1995) in East and West Germany separately for the 1995-2000, 2001-2005 and 2006-2010 period. ${ }^{24}$ Figure 13 suggests some employment polarization in East (shown in the left panel) and West Germany (shown in the right panel). Employment polarization is strongest during the 1995-2000 period (the orange line)

\footnotetext{
${ }^{23}$ We use the criterion-validated task measures following Rohrbach-Schmidt and Tiemann (2013). The four task measures are calculated from twelve questions on the task content of jobs. Analytical tasks include organizing, conducting research and measuring. We classify training, consulting, buying, advertising and negotiating as interactive tasks. Non-routine manual tasks are repairing and nursing, while routine manual tasks include monitoring and producing.

${ }^{24}$ We limit the time period to the period from 1995 to 2010 for two reasons: first, we want to understand the rise in top end wage inequality, which reversed since 2010. Second, by restricting the period of analysis until 2010, we avoid inconsistencies in the reporting of occupations in 2011.
} 
Figure 13: Occupational Shifts Along the Skill Distribution
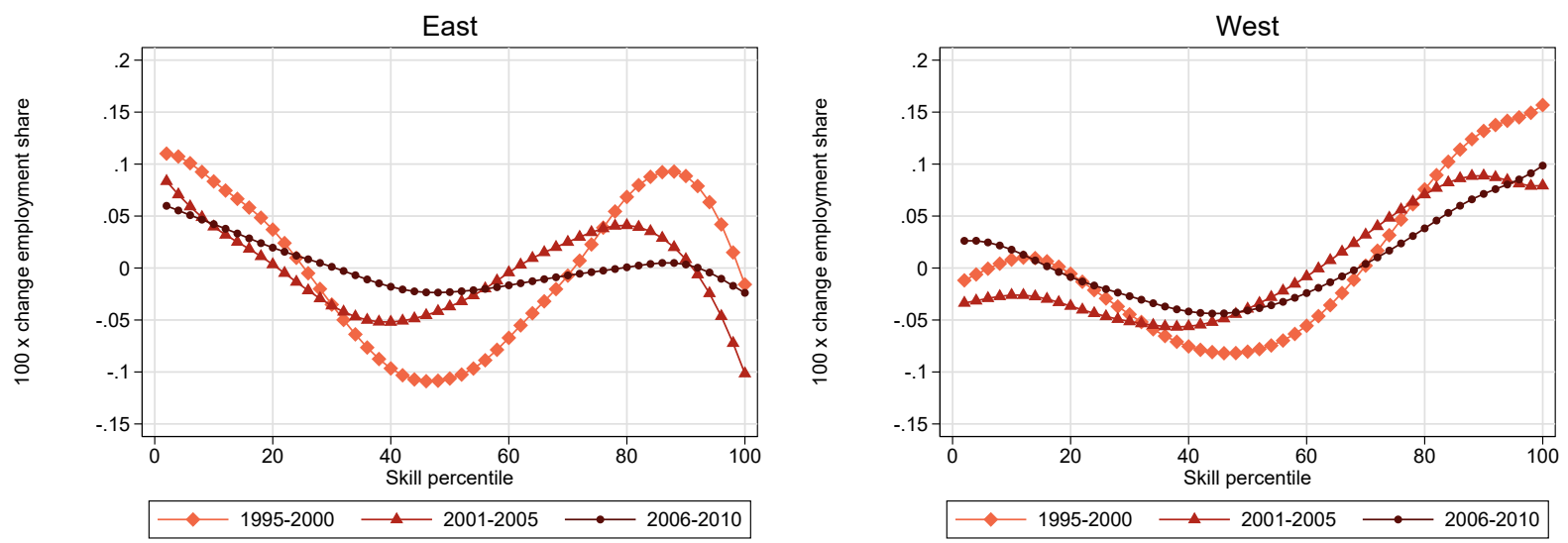

Note.- The figures plot the relative changes in employment share for occupations along the skill distribution. Source: $2 \%$ SIAB Sample for male full-time workers between the ages of 20 and 62 .

and starts to level off across the skill distribution in later periods (the dark red lines). Figure 13 also shows important differences between East and West: in East Germany, employment at the bottom and top of the skill distribution grow by $10 \%$ between 1995 and 2000 and declines by the same amount in the middle. After 2000, there is little employment growth at the top of the skill distribution in East Germany. In West Germany, in turn, there is no employment growth at the bottom, but strong employment growth (by 15\%) at the top between 1995 and 2010 .

We next investigate whether there is any corresponding polarization in wages that follows the same pattern as employment. Hence, we compute the change in experience-adjusted occupational median wages for the three time periods along the occupational skill distribution and plot them in figure B4 in the appendix. We find no evidence for wage polarization, neither in East, nor in West Germany during the 1995-2010 period (see also Antonczyk et al. (2011) for a similar result). Rather, wages at the bottom show modest losses in all of Germany between 1995 and 2010, while wages at the top grow, especially between 1995 and 2005. In line with the strong growth in the 8550 wage gap documented in Section 3 above, the wage gains at the top are much more pronounced in East Germany: wages at the top grow by $7.5 \%$ between 1995 and 2000 and still around 6\% between 2001 and 2005. In West Germany, wages grow only by $3-4 \%$ on average over the same period.

Can we explain the rise in top wage inequality before 2009 by the employment changes across occupations observed in figure 13? To investigate this question, we again use the DiNardo et al. (1996) approach to re-weigh occupational employment to their 1995 shares. ${ }^{25}$ The approach again relies on the assumption that the observed employment shifts between 1995 and 2010 do not affect

\footnotetext{
${ }^{25} \mathrm{An}$ alternative approach would be to reweigh by task intensities or a combined routinization index (as introduced by Autor and Dorn, 2013). As these alternative measures are calculated at the occupation level, occupations with the same task intensities would be assigned identical weights in the DFL approach. Our approach is more flexible as we allow separate weights for each occupation.
} 
skill returns seems to be satisfied given that we find no wage polarization (see figure B4). Figure

Figure 14: Log Wage Gaps - DFL Reweighting to 1995 Occupational Structure
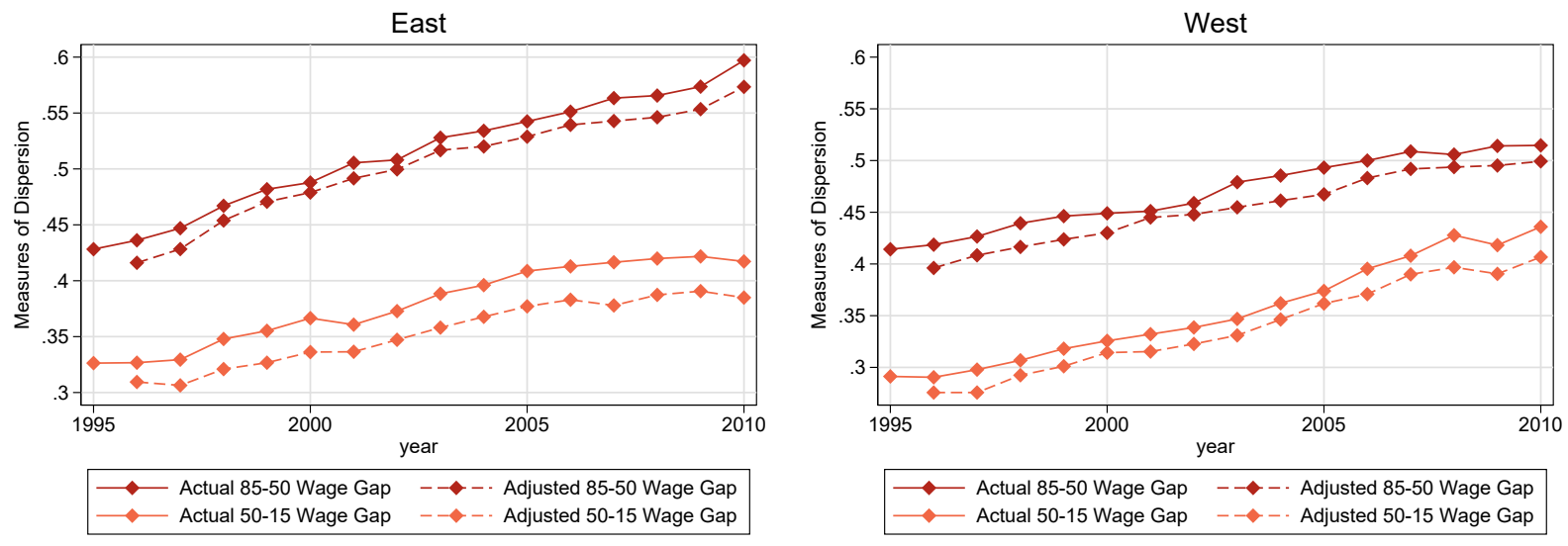

Note.- The figures plot the wage gap between the 85th and 50th percentiles and the wage gap between the 50th and 15th percentiles. The solid lines show the observed wage gaps, while the dashed lines show the counterfactual wage gaps when the occupational employment shares are re-weighted to their 1995 level. The left panel refers to East Germany, the right one to West Germany.

Source: $2 \%$ SIAB Sample for male full-time workers between the ages of 20 and 62 .

14 plots the actual 85-50 and 50-15 log wage gaps and the counterfactual wage gaps based on the re-weighted occupational structure. Changes in the occupational structure play a minor role for the lower end of the wage distribution, esp. in East Germany. Even more importantly, figure 14 shows that changes in the occupational structure play no role for the rise in top wage inequality in East and West Germany between 1995 and 2009. Hence, routine-biased technological change and the employment polarization of the wage distribution cannot explain the rising wage inequality at the top prior to 2009.

\subsection{The Role of International Trade}

Figure 12 indicates that between-industry shifts account for a sizable share of the rise in top wage inequality in East Germany. Globalisation with its accompanying reorganization of production and cross-border value chains might be an important driver of top end inequality during the 1990s and 2000s. Specifically, Eastern Europe and especially China have been integrated into the world market over our sample period. As a result, Germany's open economy experienced an increased demand for export goods and increasing competition from imports (e.g. Dauth et al., 2014, 2017b). Further, international trade affected some industries much more than others: exportoriented industries (like automobiles or machinery, for examples) experienced sizable growth, while industries facing import competition (like textiles, furniture or toys) suffered employment declines (see figure B1). While East Germany had traditionally a smaller export sector, employment shares in manufacturing, services and construction have moved closer to West German levels over time.

To examine the impact of sectoral employment changes on wage inequality, we re-weigh in- 
dustry employment shares to their 1995 values using the DiNardo et al. (1996) approach. We present both actual and adjusted 85-50 and 50-15 log wage gaps in figure 15. Shifts in industrial

Figure 15: Log Wage Gaps - DFL Reweighting to 1995 Industry Structure
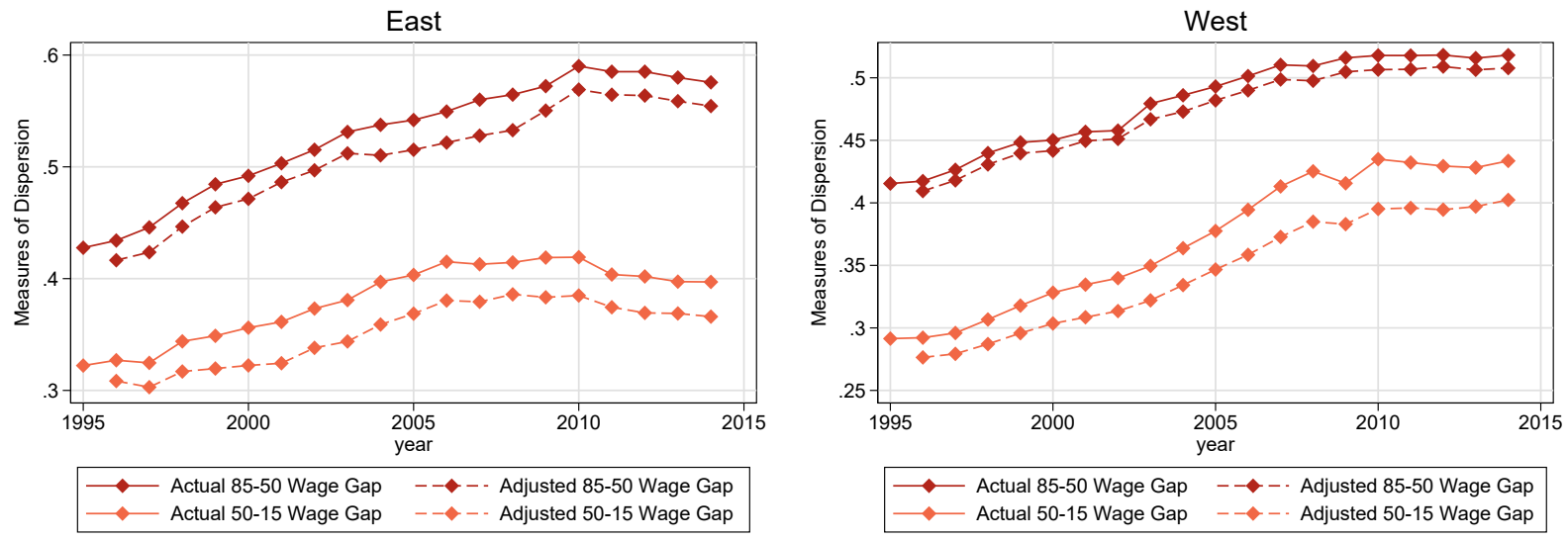

Note.- The figures plot the wage gap between the 85th and 50th percentiles and the wage gap between the 50th and 15th percentiles. The solid lines shows the observed wage gaps, while the dashed lines show the counterfactual wage gaps calculated for the industry shares observed in 1995. The left panel refers to East Germany, the right one to West Germany.

Source: $2 \%$ SIAB Sample for male full-time workers between the ages of 20 and 62 .

employment shares have only a small effect on the 85-50 wage gap. However, the re-weighting procedure abstracts from changes in industry premiums over time. And as industry fixed effects explain a sizable share of upper-tail wage inequality, we next investigate whether trade-related wage premiums changed over our sample period.

To do so, we analyze how industry-level trade exposures to new trading partners in Eastern Europe and China have affected manufacturing wages. ${ }^{26}$ Following Dauth et al. (2017b), we define the export exposure of an industry as the annual share of exports to new trading partners in its total exports. Import exposures are define accordingly. Our estimation of the effect of trade exposures on wages is then given by

$$
w_{i j t}=\beta_{1} \operatorname{IMExP}_{j t}+\beta_{2} \operatorname{ExExP}_{j t}+\gamma_{i}+\phi_{t}+\psi_{J}+\varepsilon_{i j t},
$$

where $w_{i j t}$ represents $\log$ wages of individual $i$ employed in manufacturing industry $j$ in year $t$ relative to 1995. The variables $\operatorname{IMExP}_{j t}$ and $\operatorname{ExExP}_{j t}$ measure the trade exposure to Eastern European countries and China for each 3-digit manufacturing industry in each year. To control for contemporaneous demand shocks, we implement the instrumental variable approach of Autor et al. (2013) where we instrument Germany's exposure to import and exports from Eastern Europe and China with trade exposures of eight other Western economies. ${ }^{27}$ All specifications also control

\footnotetext{
${ }^{26}$ The countries included for the calculation of the trade exposures are Azerbaijan, Bulgaria, Belarus, China, Czech Republic, Estonia, Georgia, Hungary, Kazakhstan, Kyrgyzstan, Lithuania, Latvia, Moldova, Poland, Romania, Russia, Slovakia, Slovenia, Tajikistan, Turkmenistan, Ukraine and Uzbekistan.

${ }^{27}$ These are Australia, Canada, Great Britain, Japan, Norway, New Zealand, Singapore and Sweden
} 
for year fixed effects $\phi_{t}$, person fixed effects $\gamma_{i}$ and 2-digit industry fixed effects $\psi_{J}$. We cluster standard errors at the industry-year level in all specifications. In addition, we have divided the

Table 5: Effects of trade on manufacturing wages

\begin{tabular}{lccccccc}
\hline & & & & & & & \\
& & $(2)$ & $(3)$ & $(4)$ & $(5)$ & $(6)$ \\
& & East & & & West & \\
& Below 15 & 15 to 50 & 50 to 85 & & Below 15 & 15 to 50 & 50 to 85 \\
\cline { 2 - 5 } IMExP & 0.044 & $-0.1885^{* * *}$ & $-0.2822^{* * *}$ & & -0.0234 & $-0.111^{* * *}$ & $-0.1509^{* * *}$ \\
& $(0.0758)$ & $(0.043)$ & $(0.0475)$ & & $(0.0275)$ & $(0.0038)$ & $(0.0119)$ \\
ExExP & 0.1115 & $0.1704^{* * *}$ & $0.1633^{* * *}$ & $0.1464^{* * *}$ & $0.0587^{* * *}$ & $0.1615^{* * *}$ \\
& $(0.1114)$ & $(0.0453)$ & $(0.0564)$ & & $(0.038)$ & $(0.0142)$ & $(0.0187)$ \\
& & & & & & \\
\hline Emp. Share Export Mft. & $10.01 \%$ & $11.22 \%$ & $10.67 \%$ & $8.82 \%$ & $12.62 \%$ & $22.24 \%$ \\
Emp. Share Import Mft. & $6.56 \%$ & $12.77 \%$ & $11.14 \%$ & $5.93 \%$ & $12.52 \%$ & $15.48 \%$ \\
\hline Year fixed effects & YES & YES & YES & YES & YES & YES \\
Person fixed effects & YES & YES & YES & YES & YES & YES \\
2-digit industry fixed effects & YES & YES & YES & YES & YES & YES \\
Observations & 29,604 & 63,038 & 69,038 & 222,170 & 518,301 & 518,322 \\
Within $R^{2}$ & 0.0330 & 0.0824 & 0.0606 & 0.0240 & 0.1129 & 0.2819 \\
\hline
\end{tabular}

NotE.-The table presents regression of log wages on import and export exposures of 3-digit industries. We split the sample along percentile categories and compute separate regressions for workers earning below the 15th percentile ('Below 15'), workers earning between the 15 th and 50th percentiles (' 15 to 50 '), workers earning between the 50th and 85th percentiles ('50 to $85^{\prime}$ ). We also report the 2014 employment shares of export and import manufacturing for the seperate percentile categories.

Source: $2 \%$ SIAB Sample for male full-time workers between 20 and 62 years of age

sample into wage percentile categories, which we calculate from the wage percentiles for the entire period. The percentile categories are workers earning below the 15th percentile ('Below 15'), workers earning between the 15 th and 50 th percentiles (' 15 to 50 '), workers earning between the 50 th and 85 th percentiles ('50 to 85 ').

The results of these regressions are shown in table 5. Interestingly, import competition has negative wage effects at the top but the effects are much stronger in East Germany than in West Germany. In contrast, important competition has no or smaller wage effects below the 15th and below the 50th percentiles. In contrast, export exposure has strong positive wage effects at the top of the wage distribution in East and West Germany. However, even the East German employee earning between 15th and 50th percentiles benefits from rising exports. Between 1995 and 2014, the average export (import) exposure in East Germany increased by 12.6 (15.5) percentage points while it increased by 14 (16.9) p.p. in the West. Evaluating the effect of trade exposures on East German manufacturing wages between the 15th and 50th percentiles implies a $2.9 \%$ decline in wages associated with import exposure and a $2.1 \%$ wage increase related to export exposure. Similarly, wages between the 50th and 85th percentiles, export exposure increases wages by $2.5 \%$, while import exposure reduces wages by $4.3 \%$.

Overall then, the wage effects of import and export exposure are very similar for East German employees earning between the 15th and 85th percentiles. Furthermore, (export and import) manufacturing accounts for a comparatively small share of employment, the growth in trade with new 
trading partners do not play an important role for explaining the rise in top end wage inequality. ${ }^{28}$

\section{Conclusion}

Wage inequality has widened in both East and West Germany between 1995 and 2009, with wage dispersion in East Germany exceeding West Germany, especially at the top of the distribution. Since 2009 wage inequality is no longer rising in Germany and has even been declining in East Germany.

Compositional changes of the workforce and selection along the employment margin play only a minor role as does the decline of union coverage for the rise in wage inequality. Conversely, the introduction of minimum wages in some industries explains the complete reversal in wage inequality at bottom of the distribution after 2009. Changes on the demand side seem to be at the root of the rise in wage dispersion at the top.

We also show that two major demand-side forces do not explain the rise in East German inequality at the top: Even though routine-biased technological change leads to employment polarization, it has little effect on the East or West German wage structure. Trade exposures to Eastern Europe and Chine, in turn, are much less important for the East German wage structure, due to its smaller and less export-oriented manufacturing sector.

The trade exposure to Eastern European countries and China, on the other hand, is far less important for the wage structure in the East than in the West, due to the smaller and less exportoriented manufacturing sector in East Germany.

\footnotetext{
${ }^{28}$ Employees earning between the 50th and 85 th percentiles in West Germany are much more likely to be employed in manufacturing. Furthermore, trade exposure is associated with smaller wage gains for wages between the 15th and 50th percentiles and large gains for workers earning above the median wage. Thus, trade exposure plays a larger role for upper-tail wage inequality in West Germany than in East Germany.
} 


\section{References}

Acemoglu, Daron and David Autor (2011) "Skills, Tasks, and Technologies: Implications for Employment and Earnings," in Orley Ashenfelter and David Card eds. Handbook of Labor Economics, Vol. 4B: Elsevier, pp. 1043-1171.

Akerlof, George, Andrew Rose, Janet Yellen, and Helga Hessenius (1991) "East Germany in from the Cold: The Economic Aftermath of Currency Union," Brookings Papers on Economic Activity, Vol. 22, pp. 1-106.

Antonczyk, Dirk, Bernd Fitzenberger, and Katrin Sommerfeld (2010) "Rising Wage Inequality, the Decline of Collective Bargaining, and the Gender Wage Gap," Labour Economics, Vol. 17, pp. $835-847$.

(2011) "Anstieg der Lohnungleichheit, Rückgang der Tarifbindung und Polarisierung," Zeitschrift für Arbeitsmarktforschung, Vol. 44, pp. 15-27.

Aretz, Bodo, Melanie Arntz, and Terry Gregory (2013) "The Minimum Wage Affects Them All: Evidence on Employment Spillovers in the Roofing Sector," German Economic Review, Vol. 14, pp. 282-315.

Arntz, Melanie, Christina Gathmann, and Franziska Lembcke (2014) "Permanent Changes in the Wage Structure and the East German Fertility Crisis," Working Paper, Department of Economics, University of Heidelberg.

Autor, David H. and David Dorn (2013) "The Growth of Low-Skill Service Jobs and the Polarization of the US Labor Market," American Economic Review, Vol. 103, pp. 1553-97.

Autor, David H., David Dorn, and Gordon H. Hanson (2013) "The China Syndrome: Local Labor Market Effects of Import Competition in the United States," American Economic Review, Vol. 103, pp. 2121-68.

Autor, David H, David Dorn, and Gordon H Hanson (2016a) "The China shock: Learning from labor-market adjustment to large changes in trade," Annual Review of Economics, Vol. 8, pp. 205-240.

Autor, David H., Lawrence F. Katz, and Melissa S. Kearney (2008) "Trends in U.S. Wage Inequality: Revising the Revisionists," Review of Economics and Statistics, Vol. 90, pp. 300-323.

Autor, David H., Alan Manning, and Christopher L. Smith (2016b) "The Contribution of the Minimum Wage to US Wage Inequality over Three Decades: A Reassessment," American Economic Journal: Applied Economics, Vol. 8, pp. 58-99.

Biewen, Martin (2001) "Measuring the effects of socio-economic variables on the income distribution: An application to the East German transition process," Review of Economics and Statistics, Vol. 83, pp. 185-190.

Bound, John and George Johnson (1992) "Changes in the Structure of Wages in the 1980's: An Evaluation of Alternative Explanations," American Economic Review, Vol. 82, pp. 371-392.

Burda, Michael C. (2008) "What Kind of Shock Was It? Regional Integration and Structural Change in Germany after Unification," Journal of Comparative Economics, Vol. 36, pp. 557 567.

Burda, Michael C. and Stefanie Seele (2016) No Role for the Hartz Reforms? Demand and Supply Factors in the German Labor Market, 1993-2014: Working Paper, Humboldt-Universität zu Berlin. 
Burda, Michael C. and Battista Severgnini (2018) "Total Factor Productivity Convergence in German States since Reunification: Evidence and Explanations," Journal of Comparative Economics, Vol. 46, pp. 192-211.

Burda, Michael and Jennifer Hunt (2001) "From Reunification to Economic Integration: Productivity and the Labor Market in Eastern Germany," Brookings Papers on Economic Activity, Vol. 2 , pp. 1-92.

Card, David (1992) "The Effect of Unions on the Distribution of Wages: Redistribution or Relabelling?"Technical report, NBER Working Paper No. 4195.

Card, David and John E. DiNardo (2002) "Skill-Biased Technological Change and Rising Wage Inequality: Some Problems and Puzzles," Journal of Labor Economics, Vol. 20, pp. 733-783.

Card, David, Joerg Heining, and Patrick Kline (2013) "Workplace Heterogeneity and the Rise of German Wage Inequality," Quarterly Journal of Economics, Vol. 128, pp. 967-1015.

Card, David and Thomas Lemieux (2001) "Can Falling Supply Explain the Rising Return to College for Younger Men? A Cohort-Based Analysis*," The Quarterly Journal of Economics, Vol. 116, pp. 705-746.

Card, David, Thomas Lemieux, and W. Craig Riddell (2004) "Unions and Wage Inequality," Journal of Labor Research, Vol. 25, pp. 519-559.

Chandra, Amitabh (2003) "Is the Convergence of the Racial Wage Gap Illusory?" Working Paper 9476, National Bureau of Economic Research.

Chevalier, Arnaud and Olivier Marie (2017) "Economic Uncertainty, Parental Selection, and Children's Educational Outcomes," Journal of Political Economy, Vol. 125, pp. 393-430.

Dauth, Wolfgang, Sebastian Findeisen, and Jens Südekum (2014) "The Rise of the East and the Far East: German Labor Markets and Trade Integration," Journal of the European Economic Association, Vol. 12, pp. 1643-1675.

Dauth, Wolfgang, Sebastian Findeisen, Jens Südekum, and Nicole Woessner (2017a) "German Robots - The Impact of Industrial Robots on Workers," Discussion Paper 205, CEPR.

Dauth, Wolfgang, Sebastian Findeisen, and Jens Suedekum (2017b) "Trade and Manufacturing Jobs in Germany," American Economic Review Papers and Proceedings, Vol. 107, pp. 337-42.

DiNardo, John, Nicole M Fortin, and Thomas Lemieux (1996) "Labor Market Institutions and the Distribution of Wages, 1973-1992: A Semiparametric Approach," Econometrica, Vol. 64, pp. 1001-1044.

Dustmann, Christian, Bernd Fitzenberger, Alexandra Spitz-Oener, and Uta Schönberg (2014) "From Sick Man of Europe to Economic Superstar: Germany's Resurgent Economy," Journal of Economic Perspectives, Vol. 28, pp. 167-188.

Dustmann, Christian, Johannes Ludsteck, and Uta Schönberg (2009) "Revisiting the German Wage Structure," Quarterly Journal of Economics, Vol. 124, pp. 843-81.

Farber, Henry S., Daniel Herbst, Ilyana Kuziemko, and Suresh Naidu (2018) "Unions and Inequality Over the Twentieth Century: New Evidence from Survey Data," Working Papers 620, Princeton University, Department of Economics, Industrial Relations Section.

Fitzenberger, Bernd and Annabelle Doerr (2016) "Konzeptionelle Lehren aus der ersten Evaluationsrunde der Branchenmindestlöhne in Deutschland," Journal for Labour Market Research, Vol. 49, pp. 329-347. 
Fitzenberger, Bernd, Karsten Kohn, and Alexander C. Lembcke (2013) "Union Density and Varieties of Coverage: The Anatomy of Union Wage Effects in Germany," ILR Review, Vol. 66, pp. 169-197.

Fitzenberger, Bernd, Aderonke Osikominu, and Robert Völter (2006) "Imputation Rules to Improve the Education Variable in the IAB Employment Subsample," Schmollers Jahrbuch: Journal of Applied Social Science Studies / Zeitschrift für Wirtschafts- und Sozialwissenschaften, Vol. 126, pp. $405-436$.

Fuchs-Schündeln, Nicola, Dirk Krüger, and Mathias Sommer (2010) "Inequality Trends for Germany in the Last Two Decades: A Tale of Two Countries," Review of Economic Dynamics, Vol. 13, pp. 103-132.

Fuchs-Schündeln, Nicola and Matthias Schündeln (2009) "Who Stays, Who Goes, Who Returns?," Economics of Transition, Vol. 17, pp. 703-738.

Gathmann, Christina and Uta Schönberg (2010) "How General Is Human Capital? A Task-Based Approach," Journal of Labor Economics, Vol. 28, pp. 1-49.

Gaulier, Guillaume and Soledad Zignago (2010) "BACI: International Trade Database at the Product-Level. The 1994-2007 Version," Working Papers 2010-23, CEPII research center.

German Federal Statistical Office (2017) "Database of the Universally Binding Collective Agreements in Germany," Wiesbaden.

Goos, Maarten, Alan Manning, and Anna Salomons (2009) "Job Polarization in Europe," American Economic Review, Vol. 99, pp. 58-63.

(2014) "Explaining Job Polarization: Routine-Biased Technological Change and Offshoring," American Economic Review, Vol. 104, pp. 2509-26.

Hartung, Benjamin, Philip Jung, and Moritz Kuhn (2018) "What Hides Behind the German Labor Market Miracle? Unemployment Insurance Reforms and Labor Market Dynamics,"Technical report, CESifo Working Paper No. 7379.

Hunt, Jennifer (2001) "Post-Unification Wage Growth in East Germany," Review of Economics and Statistics, Vol. 83, pp. 190-195.

(2002) "The Transition in East Germany: When is a Ten-Point Fall in the Gender Wage Gap Bad News?" Journal of Labor Economics, Vol. 20, pp. 148-169.

(2006) "Staunching Emigration from East Germany: Age and the Determinants of Migration," Journal of the European Economic Association, Vol. 4, pp. 1014-1037.

Insitut für Wirtschaftsforschung Halle (2014) "The Economic Integration of East Germany. 25 Years after the Fall of the Berlin Wall.."

Johnson, William, Yuichi Kitamura, and Derek Neal (2000) "Evaluating a Simple Method for Estimating Black-White Gaps in Median Wages," American Economic Review, Vol. 90, pp. $339-343$.

Juhn, Chinhui, Kevin M. Murphy, and Brooks Pierce (1993) "Wage Inequality and the Rise in Returns to Skill," Journal of Political Economy, Vol. 101, pp. 410-442.

Jung, Philip and Moritz Kuhn (2014) "Labour Market Institutions and Worker Flows: Comparing Germany and the US," Economic Journal, Vol. 124, pp. 1317-1342.

Katz, Lawrence F. and Kevin M. Murphy (1992) "Changes in Relative Wages, 1963-1987: Supply and Demand Factors," Quarterly Journal of Economics, Vol. 107, pp. 35-78. 
Keller, Wolfgang (2000) "From Socialist Showcase to Mezzogiorno? Lessons on the Role of Technical Change from East Germany's Post-World War II Growth Performance," Journal of Development Economics, Vol. 63, pp. 485-514.

Klosterhuber, Wolfram, Patrick Lehnert, and Stefan Seth (2016) "Linked-Employer-EmployeeDaten des IAB: LIAB-Querschnittmodell 2 1993-2014 (LIAB QM2 9314)," FDZ Datenreport 2016-05, Institut für Arbeitsmarkt- und Berufsforschung (IAB), Nürnberg.

Krause, Michael U. and Harald Uhlig (2012) "Transitions in the German Labor Market: Structure and Crisis," Journal of Monetary Economics, Vol. 59, pp. 64-79.

Krebs, Tom and Martin Scheffel (2013) "Macroeconomic Evaluation of Labor Market Reform in Germany," IMF Economic Review, Vol. 61, pp. 664-701.

Launov, Andre and Klaus Wälde (2013) "Estimating Incentive and Welfare Effects of Nonstationary Unemployment Benefits," International Economic Review, Vol. 54, pp. 1159-98.

Lee, David S (1999) "Wage Inequality in the United States During the 1980s: Rising Dispersion or Falling Minimum Wage?" Quarterly Journal of Economics, Vol. 114, pp. 977-1023.

Lemieux, T. (2006) "Increasing Residual Wage Inequality: Composition Effects, Noisy Data, or Rising Demand for Skill?" American Economic Review, Vol. 96, pp. 1-64.

Ludsteck, Johann and Ulrich Thomsen (2016) "Imputation of the Working Time Information for the Employment Register Data," FDZ Methodenreport 2016-01, Institut für Arbeitsmarkt- und Berufsforschung (IAB), Nürnberg.

Neal, Derek (2004) "The Measured Black-White Wage Gap among Women Is Too Small," Journal of Political Economy, Vol. 112, pp. S1-S28.

Olivetti, Claudia and Barbara Petrongolo (2008) "Unequal Pay or Unequal Employment? A CrossCountry Analysis of Gender Gaps," Journal of Labor Economics, Vol. 26, pp. 621-654.

Orlowski, Robert and Regina T Riphahn (2009) "The East German Wage Structure After Transition," Economics of Transition, Vol. 17, pp. 629-659.

Price, Brendan (2018) "The Duration and Wage Effects of Long-Term Unemployment Benefits: Evidence from Germany‘s Hartz IV Reform,"Technical report, Discussion Paper, UC Davis.

Rohrbach-Schmidt, Daniela and Michael Tiemann (2013) "Changes in Workplace Tasks in Germany: Evaluating Skill and Task Measures," Journal for Labour Market Research, Vol. 46, pp. $215-237$.

Sinn, Hans-Werner and Frank Westermann (2001) "Two Mezzogiornos,"Technical Report 8125, NBER Working Paper.

Spitz-Oener, Alexandra (2006) "Technical Change, Job Tasks, and Rising Educational Demands: Looking outside the Wage Structure," Journal of Labor Economics, Vol. 24, pp. 235-270.

Uhlig, Harald (2008) "The Slow Decline of East Germany," Journal of Comparative Economics, Vol. 36 , pp. $517-41$. 


\section{A Data Appendix}

In addition to our main data from the social security records, we use several additional datasets to characterize the labor demand side and minimum wages in the German labor market.

\section{A.1 Sector-specific Minimum Wages}

To assess the influence of sector-specific minimum wages on the wage structure, we obtain data on minimum hourly wages listed in generally binding collective bargaining agreements from the Federal Statistical Office (German Federal Statistical Office, 2017). From the reported minimum hourly wages, we then compute minimum daily and monthly wages assuming a 30 hours work week.

The following sectors have introduced sectoral minimum wages until 2014: the main construction industry (January of 1997), roofing (October of 1997), electrical installation (June of 1997), painting and varnishing (December of 2003), buildings cleaners (June of 2007), mining (November of 2009), laundry services (November of 2009), waste management (January of 2010), the nursing and care industry (August of 2010), security services (June of 2011), temporary agency work (January of 2012), education and training services (August of 2012), scaffolding (August of 2013), stone masonry and stone carving (October of 2013), hairdressing (November of 2013), chimney sweepers (April of 2014).

\section{A.2 Task-structure of occupations}

To track labor demand changes in technology and offshoring, we use information on the task content of occupations from the 1998/99 wave of the BiBB Qualification and Career Survey (also used in Spitz-Oener, 2006; Dustmann et al., 2009; Gathmann and Schönberg, 2010). The survey asks almost 35,000 employees in East and West Germany about the content of their job. The East German sample includes about 7,000 observations, the West German one 28,000. The sample includes all workers aged 15 years and older who work in regular, paid employment for at least 10 hours per week. Apprentices or students working in a company were excluded.

Based on twelve questions about the task content of a job, we classify tasks into routine manual, non-routine manual, analytic and interactive tasks. Analytical tasks include organizing, conducting research and measuring. We classify training, consulting, buying, advertising and negotiating as interactive tasks. Non-routine manual tasks are repairing and nursing, while routine manual tasks include monitoring and producing. We then calculate each task measure using the criterionvalidated method following Rohrbach-Schmidt and Tiemann (2013).

\section{A.3 Trade Exposure}

To track the influence of trade on the wage structure, we combine the social security records with aggregate data on trade exposure at the 3-digit industry level. The trade data come from the BACI international trade database (see Gaulier and Zignago, 2010, for a detailed description), a harmonized version of the UN COMTRADE database. The data contain information on trade flows between 150 countries for more than 5000 products using the SITC rev. 2/3 classification. Using a correspondence table between SITC and 3-digit NACE codes, we then calculate industrylevel trade-flows between countries for 92 percent of all products. We focus attention to trade in manufacturing and thus drop trade in raw materials and agricultural goods. All import and export flows are converted to 2014 prices.

We then calculate industry-level export and import intensities for Germany's new trading partners in Central and Eastern Europe whose markets became accessible after the fall of the Iron Curtain. Specifically, the trading partners include: Azerbaijan, Bulgaria, Belarus, China, Czech Republic, Estonia, Georgia, Hungary, Kazakhstan, Kyrgyzstan, Lithuania, Latvia, Moldova, Poland, Romania, Russia, Slovakia, Slovenia, Tajikistan, Turkmenistan, Ukraine and Uzbekistan. The import (export) intensities are defined as the share of annual imports (exports) relative to total industry-specific German imports (exports) (see Dauth et al., 2017b, for details). 


\section{B Additional Results}

Figure B1: Net Migration between East and West Germany and from Abroad
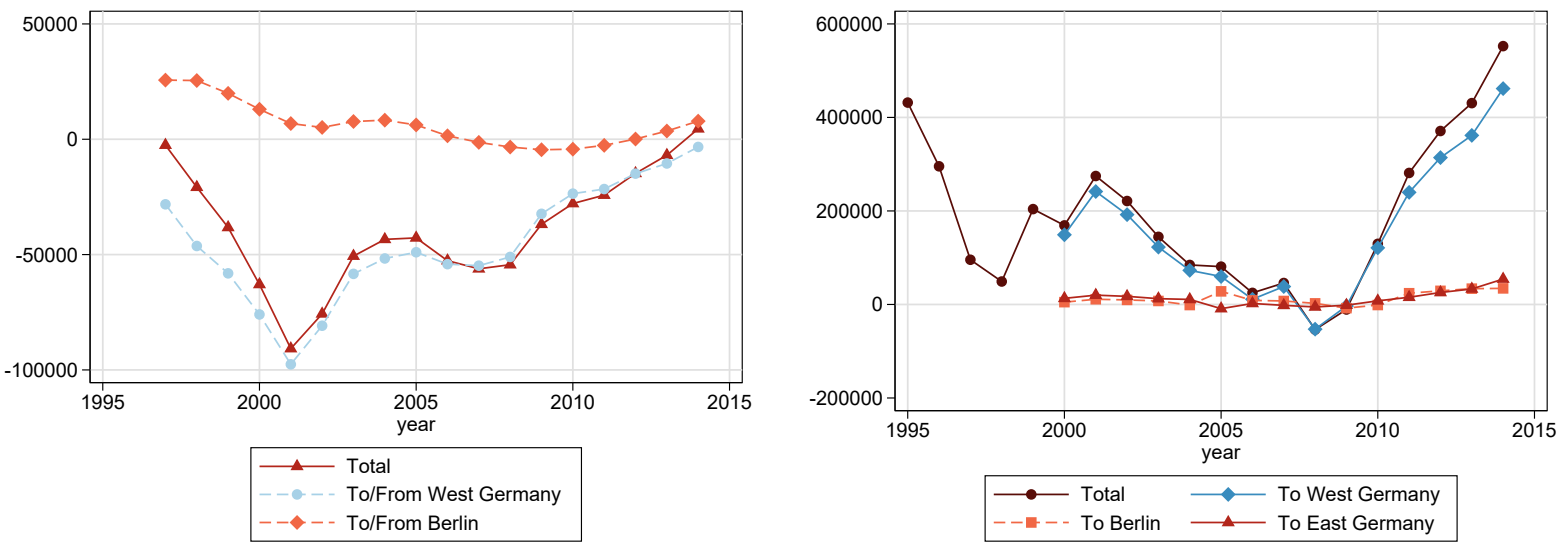

Note.- The left panel shows internal net migration between East and West Germany as well as Berlin between 1995 and 2014. The right panel shows net migration to Germany since 1995 and separately to East and West Germany as well as Berlin since 1997.

Source: Federal Statistical Office.

Figure B2: Skill Premium and Relative Skill Supplies of Medium- to Low-skilled Workers
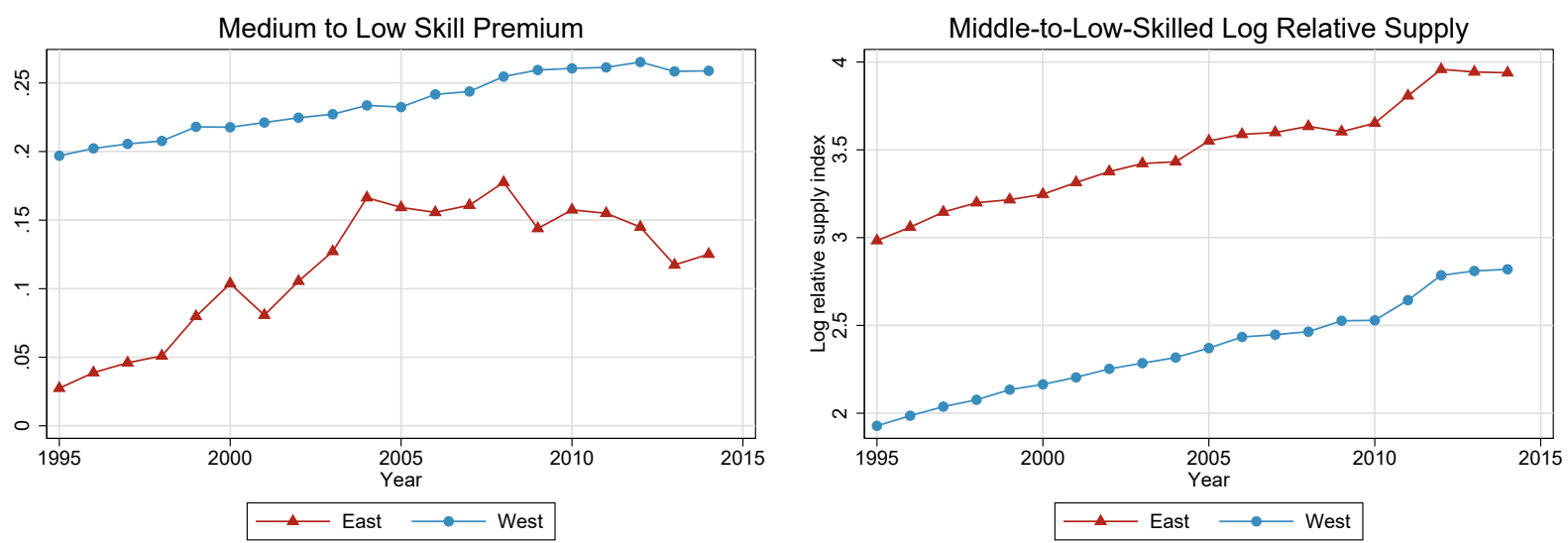

Note.- The left panel plot the age-adjusted skill premium between medium- and low-skilled men for East and West Germany. The right panel plots the relative skill supply of medium-skilled relative to low-skilled workers measured in efficiency units.

Source: $2 \%$ SIAB Sample for male full-time workers between the ages of 20 and 62 . 
Figure B3: Occupational task inputs
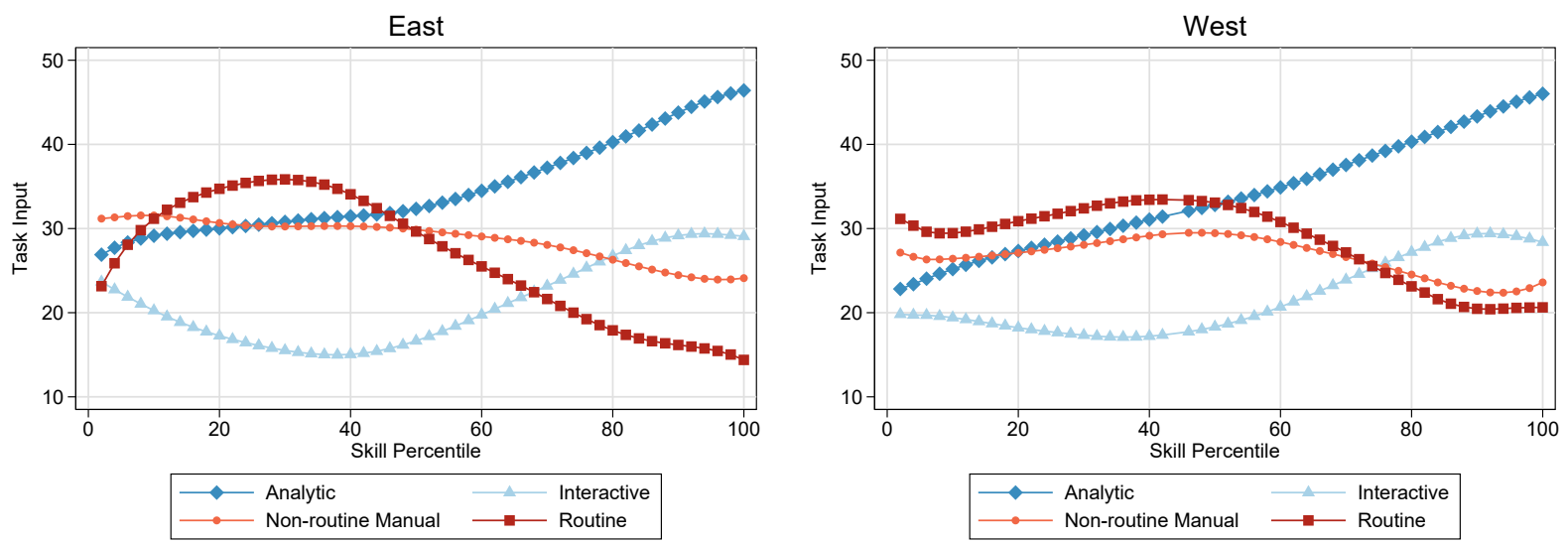

Note.- The figures plots along task inputs across the occupational skill distribution. Source: 2\% SIAB Sample for male full-time workers between the ages of 20 and 62 .

Figure B4: Occupational median wage shifts along the skill distribution
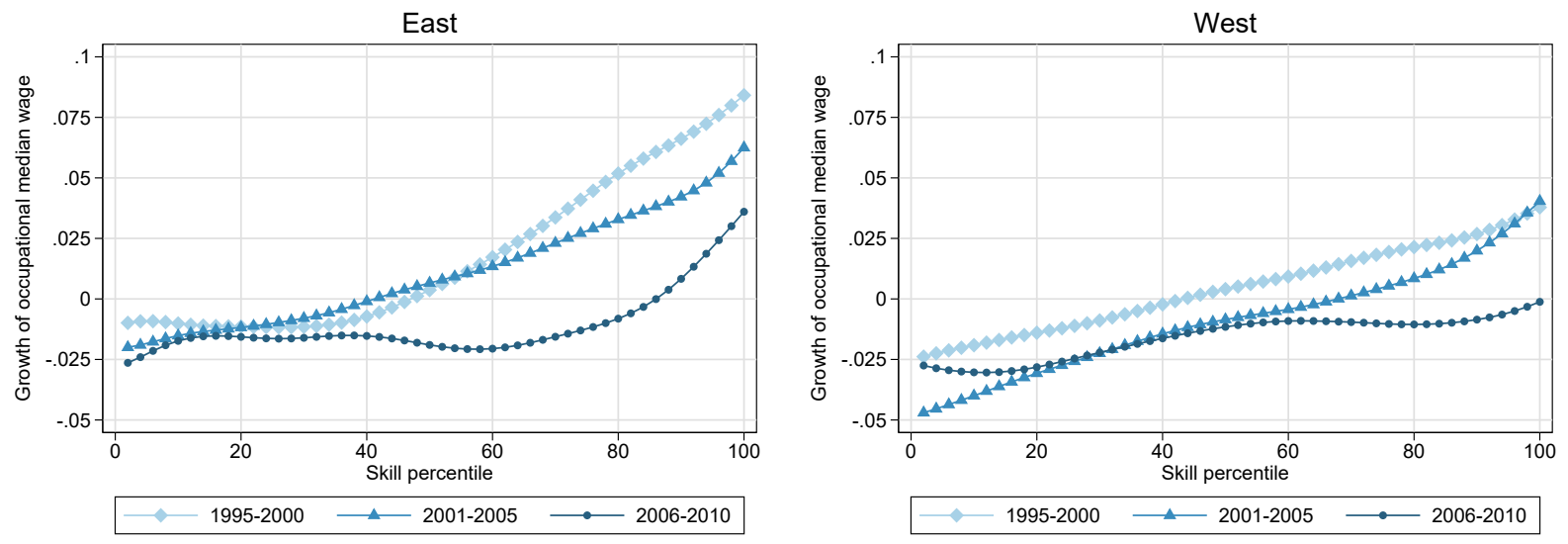

Note.- The figures plot the change in occupational median wages along the skill distribution. Source: $2 \%$ SIAB Sample for male full-time workers between the ages of 20 and 62 . 
Table B1: Summary Statistics

\begin{tabular}{|c|c|c|c|c|c|c|}
\hline & \multicolumn{6}{|c|}{ Monthly Wages } \\
\hline & 1995 & $\begin{array}{l}\text { East } \\
2004\end{array}$ & 2014 & 1995 & $\begin{array}{l}\text { West } \\
2004\end{array}$ & 2014 \\
\hline Mean & 2598 & 2733 & 2836 & 3668 & 3822 & 3883 \\
\hline Standard Deviation & 1069 & 1403 & 1470 & 1427 & 1844 & 1955 \\
\hline 15-percentile & 1696 & 1593 & 1620 & 2492 & 2345 & 2220 \\
\hline 50-percentile & 2350 & 2368 & 2400 & 3334 & 3368 & 3420 \\
\hline 85 -percentile & 3606 & 4039 & 4290 & 5045 & 5473 & 5700 \\
\hline
\end{tabular}

\begin{tabular}{|c|c|c|c|c|c|c|}
\hline & \multicolumn{6}{|c|}{ Sectoral Employment Shares } \\
\hline & \multicolumn{3}{|c|}{ East } & \multicolumn{3}{|c|}{ West } \\
\hline & 1995 & 2004 & 2014 & 1995 & 2004 & 2014 \\
\hline Export Manufacturing & $7.63 \%$ & $10.14 \%$ & $10.88 \%$ & $17.93 \%$ & $18.04 \%$ & $17.40 \%$ \\
\hline Import Manufacturing & $9.71 \%$ & $10.50 \%$ & $10.98 \%$ & $17.49 \%$ & $14.72 \%$ & $13.04 \%$ \\
\hline Services & $60.77 \%$ & $66.24 \%$ & $66.38 \%$ & $52.66 \%$ & $58.42 \%$ & $61.20 \%$ \\
\hline Construction & $17.57 \%$ & $10.03 \%$ & $9.03 \%$ & $9.08 \%$ & $6.57 \%$ & $6.30 \%$ \\
\hline Other & $4.33 \%$ & $3.10 \%$ & $2.74 \%$ & $2.84 \%$ & $2.25 \%$ & $2.06 \%$ \\
\hline
\end{tabular}

GDP per capita

Unemployment rate

Employment rate

\begin{tabular}{ccccccc}
\multicolumn{7}{c}{ Aggregate Variables } \\
& East & & & & West \\
1995 & 2004 & 2014 & & 1995 & 2004 & 2014 \\
\hline 21830 & 23825 & 27618 & & 32180 & 33571 & 36898 \\
$13.90 \%$ & $18.40 \%$ & $9.80 \%$ & & $8.10 \%$ & $8.50 \%$ & $5.90 \%$ \\
$43.99 \%$ & $41.69 \%$ & $47.77 \%$ & & $44.25 \%$ & $43.63 \%$ & $49.77 \%$
\end{tabular}

NOTE.- The table shows summary statistics of wages, sectoral composition and aggregate indicators of economic activity for East and West Germany in 1995, 2004 and 2014. The employment rate is calculated relative to the total population in each region and year.To do so, we divide the manufacturing sector into export- and import-intensive industries. We subdivide the manufacturing sector into import and export manufacturing. Following Dauth et al. (2017a), we define export manufacturing if the change in net exports to the trading partners from Eastern Europe and China was above the median change for manufacturing as a whole between 1995 and 2014. The new trading partners included are Azerbaijan, Bulgaria, Belarus, China, Czech Republic, Estonia, Georgia, Hungary, Kazakhstan, Kyrgyzstan, Lithuania, Latvia, Moldova, Poland, Romania, Russia, Slovakia, Slovenia, Tajikistan, Turkmenistan, Ukraine and Uzbekistan. Similarly, manufacturing industries are import-intensive if their net exports are below the median change for manufacturing as a whole over the same period.

Source: $2 \%$ SIAB Sample for German male full-time workers between 20 and 62 years of age 
Table B2: West German Wage Inequality by Education and Age

\begin{tabular}{|c|c|c|c|c|c|c|c|c|c|}
\hline & \multicolumn{9}{|c|}{ Low Education } \\
\hline & \multicolumn{2}{|c|}{1995} & \multicolumn{2}{|c|}{2004} & \multicolumn{2}{|c|}{2014} & 1995 & 2004 & 2014 \\
\hline & $50-15$ gap & 85-50 gap & $50-15$ gap & 85-50 gap & $50-15$ gap & 85-50 gap & \multicolumn{3}{|c|}{ Employment Share } \\
\hline $20-36$ & 0.32 & 0.23 & 0.53 & 0.34 & 0.39 & 0.37 & $5.0 \%$ & $2.9 \%$ & $1.9 \%$ \\
\hline $37-47$ & 0.24 & 0.23 & 0.34 & 0.25 & 0.45 & 0.32 & $4.2 \%$ & $3.6 \%$ & $1.5 \%$ \\
\hline $48-62$ & 0.22 & 0.23 & 0.28 & 0.24 & 0.39 & 0.27 & $4.2 \%$ & $2.9 \%$ & $2.3 \%$ \\
\hline \multirow[t]{4}{*}{ All } & 0.28 & 0.22 & 0.45 & 0.27 & 0.46 & 0.33 & $13.5 \%$ & $9.4 \%$ & $5.8 \%$ \\
\hline & \multicolumn{9}{|c|}{ Medium Education } \\
\hline & \multicolumn{2}{|c|}{1995} & \multicolumn{2}{|c|}{2004} & \multicolumn{2}{|c|}{2014} & 1995 & 2004 & 2014 \\
\hline & 50-15 gap & 85-50 gap* & 50-15 gap & 85-50 gap* & 50-15 gap & 85-50 gap* & \multicolumn{3}{|c|}{ Employment Share } \\
\hline $20-36$ & 0.25 & 0.28 & 0.33 & 0.33 & 0.33 & 0.35 & $32.1 \%$ & $24.2 \%$ & $21.3 \%$ \\
\hline $37-47$ & 0.27 & 0.35 & 0.31 & 0.37 & 0.37 & 0.42 & $23.9 \%$ & $30.9 \%$ & $23.2 \%$ \\
\hline $48-62$ & 0.28 & 0.38 & 0.32 & 0.43 & 0.38 & 0.43 & $20.1 \%$ & $20.4 \%$ & $29.6 \%$ \\
\hline \multirow[t]{4}{*}{ All } & 0.27 & 0.36 & 0.33 & 0.38 & 0.37 & 0.42 & $76.1 \%$ & $75.5 \%$ & $74.1 \%$ \\
\hline & \multicolumn{9}{|c|}{ High Education } \\
\hline & \multicolumn{2}{|c|}{1995} & \multicolumn{2}{|c|}{2004} & \multicolumn{2}{|c|}{2014} & 1995 & 2004 & 2014 \\
\hline & 50-15 gap* & 85-50 gap* & 50-15 gap* & 85-50 gap* & 50-15 gap* & 85-50 gap* & \multicolumn{3}{|c|}{ Employment Share } \\
\hline $20-36$ & 0.29 & 0.34 & 0.36 & 0.34 & 0.34 & 0.33 & $3.8 \%$ & $3.9 \%$ & $5.1 \%$ \\
\hline $37-47$ & 0.31 & 0.30 & 0.36 & 0.39 & 0.40 & 0.36 & $4.2 \%$ & $7.5 \%$ & $7.4 \%$ \\
\hline $48-62$ & 0.26 & 0.28 & 0.39 & 0.38 & 0.42 & 0.39 & $2.5 \%$ & $3.7 \%$ & $7.7 \%$ \\
\hline All & 0.35 & 0.33 & 0.39 & 0.40 & 0.43 & 0.40 & $10.5 \%$ & $15.1 \%$ & $20.1 \%$ \\
\hline
\end{tabular}

Note.- The table shows 85-50 and 50-15 log wage gaps in West Germany both across and within age and education groups as well their employment shares in 1995, 2004 and 2014. The results are based on imputed and hence, uncensored wages. The star denotes that the the 85th wage percentile for the high-skilled is above the censoring bound.

Source: $2 \%$ SIAB Sample for East German male full-time workers between 20 and 62 years of age 
Table B3: Log Wage Gaps after Imputation - West Germany

\begin{tabular}{|c|c|c|c|c|}
\hline & \multicolumn{4}{|c|}{ Imputation of leavers' wages } \\
\hline & \multicolumn{2}{|c|}{1996} & \multicolumn{2}{|c|}{2004} \\
\hline & 50-15 Gap & 85-50 Gap & 50-15 Gap & 85-50 Gap \\
\hline No Imputation & 0.29 & 0.42 & 0.36 & 0.49 \\
\hline Carried-forward wages & 0.31 & 0.42 & 0.38 & 0.49 \\
\hline Imputation on observables & 0.28 & 0.40 & 0.35 & 0.46 \\
\hline Leaver wages set to 50 -pct. & 0.27 & 0.39 & 0.33 & 0.45 \\
\hline \multirow[t]{4}{*}{ Leaver wages set to 15 -pct. } & 0.25 & 0.43 & 0.31 & 0.50 \\
\hline & \multicolumn{4}{|c|}{ Imputation of entrants' wages } \\
\hline & \multicolumn{2}{|c|}{2004} & \multicolumn{2}{|c|}{2014} \\
\hline & 50-15 Gap & 85-50 Gap & 50-15 Gap & 85-50 Gap \\
\hline No Imputation & 0.36 & 0.49 & 0.43 & 0.51 \\
\hline Carried-backward wages & 0.39 & 0.49 & 0.45 & 0.52 \\
\hline Imputation on observables & 0.35 & 0.47 & 0.41 & 0.49 \\
\hline Entrant wages set to 50 -pct. & 0.34 & 0.45 & 0.40 & 0.48 \\
\hline Entrant wages set to 15 -pct. & 0.32 & 0.50 & 0.38 & 0.54 \\
\hline
\end{tabular}

Note.- The table shows 50-15 and 85-50 log wage gaps including individuals who have no full-time job spell next year (top panel); and the same wage gaps when the wages of entrants in the West German labor market are included. Carried-forward wages use the panel structure to impute wages; imputation on observables predicts missing wages based on education, age and year. The last two imputation methods set missing wages to the 50 th percentile or the 15 th percentile of employees in the particular year.

Source: 2\% SIAB Sample for West German male full-time workers between 20 and 62 years of age

Table B4: Demographic Adjustments and Change in Log Wage Gaps

\begin{tabular}{|c|c|c|c|c|c|c|}
\hline & \multicolumn{6}{|c|}{ Change in 50-15 Log Wage Gap } \\
\hline & \multicolumn{3}{|c|}{ Overall Log Wage Gap } & \multicolumn{3}{|c|}{ Residual Log Wage Gap } \\
\hline & $1995-2004$ & 2004-2014 & $1995-2014$ & $1995-2004$ & 2004-2014 & $1995-2014$ \\
\hline Actual & 0.070 & -0.003 & 0.067 & 0.046 & 0.001 & 0.047 \\
\hline 1995 demographics & 0.049 & 0.011 & 0.060 & 0.028 & 0.000 & 0.028 \\
\hline 2004 demographics & 0.070 & 0.009 & 0.079 & 0.048 & -0.001 & 0.047 \\
\hline 2014 demographics & 0.075 & -0.016 & 0.060 & 0.050 & -0.027 & 0.023 \\
\hline
\end{tabular}

\begin{tabular}{|c|c|c|c|c|c|c|}
\hline & \multicolumn{6}{|c|}{ Change in 85-50 Log Wage Gap } \\
\hline & \multicolumn{3}{|c|}{ Overall Log Wage Gap } & \multicolumn{3}{|c|}{ Residual Log Wage Gap } \\
\hline & $1995-2004$ & 2004-2014 & $1995-2014$ & $1995-2004$ & $2004-2014$ & $1995-2014$ \\
\hline Actual & 0.106 & 0.047 & 0.153 & 0.079 & 0.025 & 0.104 \\
\hline 1995 demographics & 0.087 & 0.018 & 0.105 & 0.065 & 0.020 & 0.085 \\
\hline 2004 demographics & 0.112 & 0.041 & 0.153 & 0.077 & 0.026 & 0.103 \\
\hline 2014 demographics & 0.100 & 0.021 & 0.121 & 0.074 & 0.015 & 0.089 \\
\hline
\end{tabular}

Note.-The table shows the evolution of total and residual log wage gaps for the periods from 1995 to 2004 , 2004 to 2014 and 1995 to 2014 . We present both the actual change in wage gaps and changes in wage gaps where demographics are adjusting to the workforce composition of 1995, 2004 and 2014.

Source: $2 \%$ SIAB Sample for East German male full-time workers between 20 and 62 years of age 
Table B5: Entrant and Leaver Characteristics

\begin{tabular}{|c|c|c|c|c|c|c|c|c|}
\hline & \multicolumn{4}{|c|}{1995} & \multicolumn{4}{|c|}{2004} \\
\hline & \multicolumn{2}{|c|}{ Stayers } & \multicolumn{2}{|r|}{ Leavers } & \multicolumn{2}{|c|}{ Stayers } & \multicolumn{2}{|r|}{ Leavers } \\
\hline & 15 to 50 Pct. & Median & Overall & Outmigrants & 15 to 50 Pct. & Median & Overall & Outmigrants \\
\hline Mean Wage & 2026 & 2350 & 2427 & 2367 & 1973 & 2368 & 2253 & 2146 \\
\hline Std. Dev. Wage & 180 & & 1116 & 1177 & 210 & & 1272 & 1287 \\
\hline Mean Residual Wage & 2309 & 2539 & 2472 & 2611 & 2205 & 2598 & 2301 & 2370 \\
\hline Std. Dev. Residual Wage & 429 & 529 & 936 & 952 & 454 & 295 & 1080 & 1029 \\
\hline Share Low-Skilled & $4.0 \%$ & $2.7 \%$ & $5.7 \%$ & $3.8 \%$ & $2.4 \%$ & $1.5 \%$ & $5.6 \%$ & $7.0 \%$ \\
\hline Share Medium-Skilled & $92.3 \%$ & $89.1 \%$ & $77.4 \%$ & $82.2 \%$ & $93.4 \%$ & $96.9 \%$ & $78.4 \%$ & $80.8 \%$ \\
\hline Share High-Skilled & $3.7 \%$ & $8.2 \%$ & $16.9 \%$ & $14.1 \%$ & $4.3 \%$ & $1.5 \%$ & $16.0 \%$ & $12.2 \%$ \\
\hline Mean Age & 38.31 & 39.06 & 42.11 & 32.14 & 40.29 & 40.82 & 42.90 & 34.79 \\
\hline \multirow[t]{4}{*}{ Std. Dev. Age } & 10.46 & 10.26 & 12.42 & 8.95 & 10.28 & 8.98 & 12.25 & 9.84 \\
\hline & \multicolumn{4}{|c|}{2004} & \multicolumn{4}{|c|}{2014} \\
\hline & \multicolumn{2}{|c|}{ Stayers } & \multicolumn{2}{|c|}{ Entrants } & \multicolumn{2}{|c|}{ Stayers } & \multicolumn{2}{|c|}{ Entrants } \\
\hline & 15 to 50 Pct. & Median & Overall & First Entrants & 15 to 50 Pct. & Median & Overall & First Entrants \\
\hline Mean Wage & 1973 & 2368 & 2079 & 1761 & 1986 & 2400 & 2286 & 2088 \\
\hline Std. Dev. Wage & 210 & & 1111 & 989 & 208 & & 1251 & 1030 \\
\hline Mean Residual Wage & 2205 & 2598 & 2167 & 2309 & 2210 & 2563 & 2307 & 2443 \\
\hline Std. Dev. Residual Wage & 454 & 295 & 1006 & 872 & 441 & 476 & 1087 & 858 \\
\hline Share Low-Skilled & $2.4 \%$ & $1.5 \%$ & $3.4 \%$ & $13.8 \%$ & $1.6 \%$ & $2.1 \%$ & $2.3 \%$ & $8.6 \%$ \\
\hline Share Medium-Skilled & $93.4 \%$ & $96.9 \%$ & $83.7 \%$ & $72.9 \%$ & $94.0 \%$ & $90.5 \%$ & $80.6 \%$ & $65.2 \%$ \\
\hline Share High-Skilled & $4.3 \%$ & $1.5 \%$ & $12.9 \%$ & $13.3 \%$ & $4.4 \%$ & $7.4 \%$ & $17.0 \%$ & $26.3 \%$ \\
\hline Mean Age & 40.29 & 40.82 & 40.23 & 26.73 & 42.13 & 42.17 & 41.16 & 28.78 \\
\hline Std. Dev. Age & 10.28 & 8.98 & 10.08 & 8.56 & 11.37 & 11.02 & 10.80 & 7.82 \\
\hline
\end{tabular}

NoTE.- The table displays the characteristics of labor market leavers, entrants and stayers. The upper panel compares east German labor market stayers between the 15 th and 50 th wage percentile and at the median wage with all leavers (who were employed in East Germany in the year $t$, but not in $t+1$ ) and with a subgroup of leavers with a new job in West Germany in a later year both for the years 1995 and 2004 . The bottom panel compares labor market entrants (who do not have a record in $t$, but a social security record in $t+1$ ) in the 2004-2014 to stayers. We distinguish between all entrants and first entrants (who appear in the social security records for the first time).

Source: $2 \%$ SIAB Sample for East German male full-time workers between 20 and 62 years of age 
Download ZEW Discussion Papers from our ftp server:

http://ftp.zew.de/pub/zew-docs/dp/

or see:

https://www.ssrn.com/link/ZEW-Ctr-Euro-Econ-Research.html

https://ideas.repec.org/s/zbw/zewdip.html

$$
\text { // }
$$

IMPRINT

ZEW - Leibniz-Zentrum für Europäische Wirtschaftsforschung GmbH Mannheim

ZEW - Leibniz Centre for European

Economic Research

L 7,1 68161 Mannheim · Germany

Phone +49621 1235-01

info@zew.de·zew.de

Discussion Papers are intended to make results of ZEW research promptly available to other economists in order to encourage discussion and suggestions for revisions. The authors are solely responsible for the contents which do not necessarily represent the opinion of the ZEW. 